\title{
Threshold models of temporal-order judgments evaluated by a ternary response task
}

\author{
ROLF ULRICH \\ Psychologisches Institut der Universitat Tubingen, Tübingen, Federal Republic of Germany
}

\begin{abstract}
This article examines various predictions of temporal-order judgment models (triggered-moment, attention-switching, and perceptual-moment models). These model tests are based on a ternary response-category approach: In each trial two stimuli (e.g., a tone and a light) are presented at times $t_{\mathrm{x}}$ and $t_{\mathrm{y}}$, respectively. The time difference $d=t_{\mathrm{y}}-t_{\mathrm{x}}$ was varied for each trial. After each presentation the subject selected one of three possible responses ("tone and light simultaneously," "tone first," or "light first"). Two psychometric functions can be generated from these response categories. It is shown that several models of temporal-order judgments constrain the relationship between these two functions. It was examined for different data sets whether the predicted relationships are satisfied. Several violations of the predicted relationships were observed, providing strong evidence against perceptual-moment models, triggered-moment models, and certain versions of attention-switching models. The proposed tests for each model do not depend on specific distributional assumptions of perceptual latencies. A modified attention-switching model with dwell times depending on stimulus properties might account for the present findings.
\end{abstract}

The judgment of temporal order of two nearly simultaneous stimuli, such as the onsets of a tone and a light, is a very old and still unsolved problem in experimental psychology. Individual differences in the determination of stellar transit times with the eye-and-ear method evoked interest in the psychological nature of temporal-order judgments (TOJs) (Boring, 1950; Fröhlich, 1929). Astronomers and psychologists in the 19th century investigated the sources of errors of TOJs. Why does the judged temporal order of a pair of stimuli often not correspond to the actual order? Why are two stimuli judged as being successive even when they were presented simultaneously? Although this is an old problem, it still attracts many neurophysiologists and psychologists.

Several models about TOJs have been proposed in the last three decades to account for the source of judgment errors (see Sternberg \& Knoll, 1973, for an excellent review). Although the basic concepts of these TOJ models are quite different, they are difficult to discriminate empirically. This difficulty arises because the standard TOJ paradigm with binary response categories (for example, "light before tone" vs. "tone before light") does not yield powerful data to invalidate untrue models.

Allan (1975a) elaborated the standard TOJ paradigm to yield more powerful data. Her subjects were required to judge the order of two stimuli and to rate them as successive versus simultaneous. In this manner four response

This work was supported by the Deutsche Forschungsgemeinschaft (UL 88/1-1). Part of this work was described in a doctoral dissertation in psychology submitted by the author to the University of Tübingen. I would like to thank Lorraine G. Allan, Markus Giray, Harald Schmid, Dirk Vorberg, and an anonymous reviewer for helpful hints. Requests for reprints should be sent to Rolf Ulrich, University of Tübingen, Psychologisches Institut, Friedrichstrasse 21, D-7400 Tübingen, Federal Republic of Germany. categories were generated. Data from these response categories were used to establish three psychometric functions. Allan (1975a, p. 31) noted that perceptual-latency models require these three psychometric functions to be parallel if order and successiveness judgments are based on the same internal event. However, her finding of systematically nonparallel functions invalidated perceptuallatency models. This finding parallels reaction time results that also invalidate this model (Heath, 1984). Heath found a decrease of mean response times of TOJs as the interstimulus interval increased. He showed that perceptuallatency models are inconsistent with this finding. (His deduction is based on the subsidiary assumption that the perceptual latencies of the two stimuli are independent and identical exponential random variables.)

Perceptual-latency models assume that the perceived order is due to the central arrival order of the sensory volleys elicited by each stimulus at the periphery (Gibbon \& Rutschman, 1969). Imperfect TOJs are attributed solely to the variability of the arrival latencies. Another class of models-termed here threshold models-assumes that the interval between the central arrivals of the two sensory volleys is a further source for imperfect TOJs. The present paper pursues Allan's (1975a) approach to developing various tests for threshold models of TOJs.

The present paper is not the first to pursue Allan's approach. In an unpublished theoretical paper, Sternberg, Knoll, and Mallows (1975) made precise several implications for TOJ models within the framework of Allan's multiple-function approach. They considered the predictions of perceptual-latency models, which assume that the subject partitions the continuum of the arrival-latency difference into nonoverlapping regions for response generation. Sternberg et al. (1975) showed that the shape differences among the psychometric functions provide impor- 


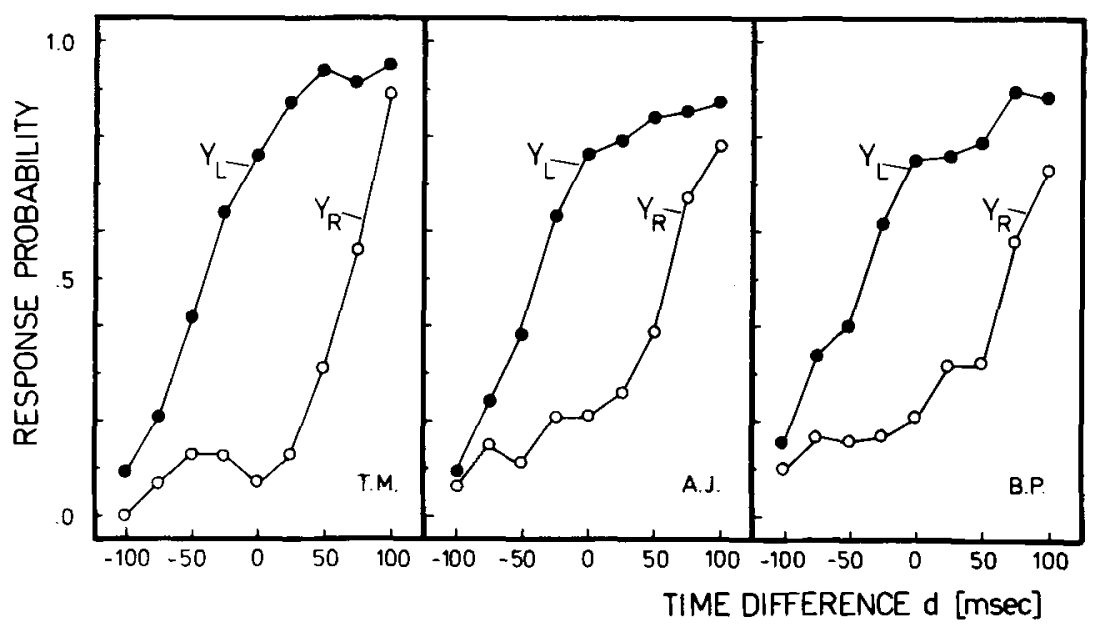

Figure 1. Functions $Y_{L}$ and $Y_{R}$ for 3 subjects (T.M., A.J., and B.P.) of Allan's (1975a) experiment. The left function is $Y_{\mathrm{L}}$ and the right one $Y_{\mathrm{R}}$. Subjects judged the temporal order of a light and a tone offset. A negative value of time difference $d$ indicates that the tone ofiset occurred before the light offiset. $Y_{R}(d)=\operatorname{Pr}$ \{ “light ofiset before tone offset" $\mid d$ \} and $Y_{L}(d)=$ $1-\operatorname{Pr}\{$ "tone offset before light ofiset" $\mid d\}$.

tant tests for TOJ models. Likewise, in this paper, I use this shape difference approach for testing threshold models.

The organization of this paper is as follows: (1) The proposed tests for threshold models require a specific approach, which is described first. (2) The concept of a general model class-the general threshold model-is developed. (3) The predictions for special cases of this model class are derived. (4) Finally, the derived predictions are checked against data reported in the literature and against the data of my own experiment. Whenever possible, I have adopted the notation and terminology suggested by Sternberg and Knoll (1973), as some readers may already be familiar with their work.

\section{THE TERNARY TOJ APPROACH}

On each experimental trial, the stimuli $S_{\mathrm{x}}$ and $S_{\mathrm{y}}$ (e.g., a tone and a light onset) are presented at times $t_{\mathrm{x}}$ and $t_{\mathrm{y}}$ $=t_{\mathrm{x}}+d$, respectively. The time difference $d \equiv t_{\mathrm{y}}-t_{\mathrm{x}}$ may be positive, zero, or negative; $d$ is randomly varied from trial to trial. After each presentation, the subject judges whether both stimuli appeared to occur simultaneously (response $s i$ ), or whether $S_{\mathrm{x}}$ appeared to occur before $S_{\mathrm{y}}$ (response $x y$ ) or after $S_{y}$ (response $y x$ ). In this way the three response probabilities $\operatorname{Pr}\{s i \mid d\}, \operatorname{Pr}\{x y \mid d\}$, and $\operatorname{Pr}\{y x \mid d\}$ are generated for each value of $d$. From studies that have used ternary TOJ designs, one can see that $\operatorname{Pr}\{x y \mid d\}$ increases with $d$ from zero to one, $\operatorname{Pr}\{y x \mid d\}$ decreases with $d$ from one to zero, and $\operatorname{Pr}\{s i \mid d\}$ obtains a maximum value at about $d=0 \mathrm{msec}$ (Allan, 1975a ${ }^{1}$; Benussi, 1913).

For the remainder of this work only the two functions $Y_{\mathbf{L}}(d) \equiv 1-\operatorname{Pr}\{y x \mid d\}$ and $Y_{\mathbf{R}}(d) \equiv \operatorname{Pr}\{x y \mid d\}$ will be required (indices $L$ and $R$ stand for left and right position in the function plot, respectively). Testable relationships between $Y_{L}$ and $Y_{R}$ will be derived from general and specific assumptions of threshold models. Figures 1 and 2 illustrate empirical functions of $Y_{L}$ and $Y_{R}$ for Allan's (1975a) and Benussi's (1913) experiments, respectively.

\section{THE GENERAL THRESHOLD MODEL OF TOJS}

The general threshold model of TOJs is shown in Figure 3. Stimuli $S_{\mathrm{x}}$ and $S_{\mathrm{y}}$ are presented at times $t_{\mathrm{x}}$ and $t_{\mathrm{y}}$. Stimulus $S_{\mathrm{x}}\left(S_{\mathrm{y}}\right)$ elicits a sensory message $m_{\mathrm{x}}\left(m_{\mathrm{y}}\right)$, which reaches some point in the brain after an arrival

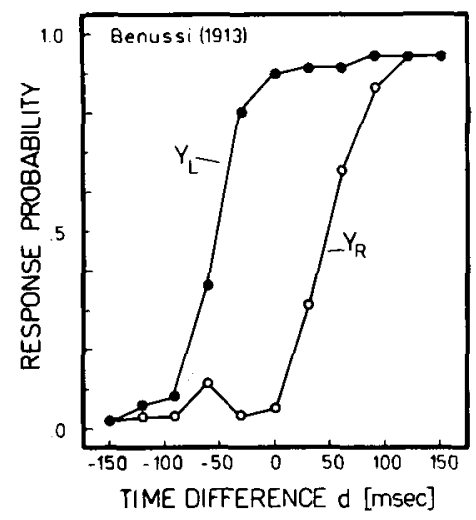

Figure 2. Functions $Y_{L}$ and $Y_{R}$ from Benussi's (1913, pp. 363-368) experiment. The left function is $Y_{L}$ and the right one $Y_{R}$. Subjects judged the temporal order of a pair of visual stimuli (a left-hand and a right-hand flash). A negative time difference $d$ indicates that the right flash occurred prior to the left flash. $Y_{R}(d)$ $=\operatorname{Pr}\{$ "left flash before right flash" $\mid d\}$ and $Y_{L}(d)=1-\operatorname{Pr}$ ("right flash before left flash"|d\}. There were 256 observations at $d=0$ msec and 128 observations at each value of $d$ different from zero. 
latency, $\mathbf{L}_{\mathbf{x}}\left(\mathbf{L}_{\mathbf{y}}\right)$. The arrival times of $m_{\mathrm{x}}$ and $m_{\mathbf{y}}$ are denoted by $\mathbf{A}_{\mathrm{x}}=\mathbf{L}_{\mathrm{x}}+t_{\mathrm{x}}$ and $\mathbf{A}_{\mathrm{y}}=\mathbf{L}_{\mathrm{y}}+t_{\mathrm{y}}=\mathbf{L}_{\mathrm{y}}+t_{\mathrm{x}}+d$, respectively. ${ }^{2}$ Neurophysiological findings (e.g., Eschweiler, Popp, Rauschecker, \& Schrader, 1984; Levick, 1973; Möcks, Gasser, \& Pham, 1984; Möcks, Gasser, Pham, \& Köhler, 1987; Rauschecker, Popp, \& Eschweiler, 1986; Zacks, 1973) and reaction time studies (e.g., Meijers \& Eijkman, 1974; Ulrich \& Stapf, 1984) suggest that latencies $\mathbf{L}_{\mathbf{x}}$ and $\mathbf{L}_{\mathbf{y}}$ vary considerably from trial to trial. Therefore it is assumed that $L_{x}$ and $L_{y}$ represent random variables.

How the responses $x y, y x$, and $s i$ are generated by threshold models can be stated with two assumptions:

Assumption 1. Assume that $m_{\mathrm{x}}$ arrives first and $m_{\mathrm{y}}$ second, that is, $\mathbf{A}_{\mathbf{y}}>\mathbf{A}_{\mathbf{x}}$ (see Figure 3, upper panel). If the interval between the two arrivals is smaller than threshold value $\mathbf{C}_{\mathbf{x y}}\left(0 \leq \mathbf{C}_{\mathrm{xy}}\right)$, then perceived simultaneity results and response si is elicited. However, if the interval is greater than this threshold value, that is, if $A_{y}>A_{x}+C_{x y}$ holds, then the arrival order is perceived and response $x y$ results.
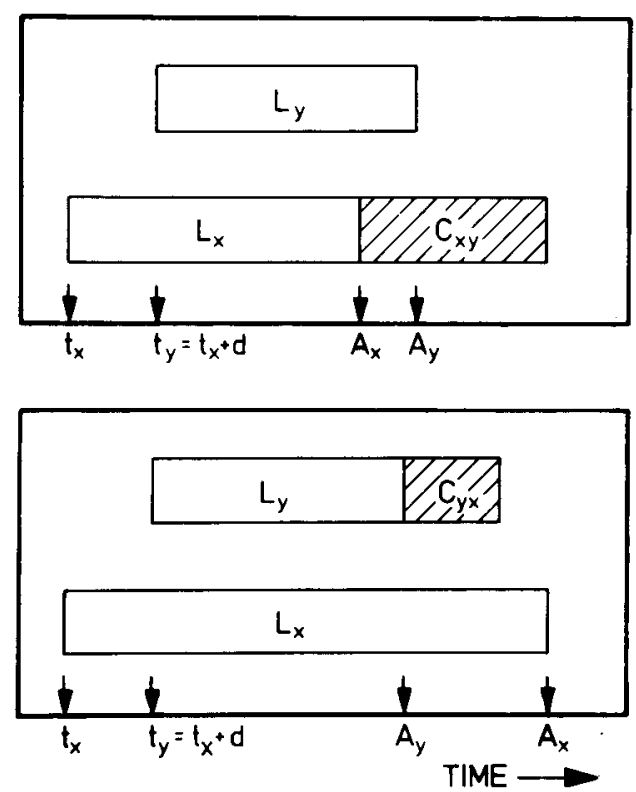

Figure 3. General threshold model of temporal-order judgments. Stimulation times of $S_{x}$ and $S_{y}$ are $t_{x}$ and $t_{y}$, respectively. The unhatched boxes represent transmission times $L_{z}$ and $L_{y}$ of the sensory messages $m_{x}$ and $m_{y}$ elicited by $S_{x}$ and $S_{y}$, respectively. $A_{x}$ and A represent the central arrival times of $m_{x}$ and $m_{y}$, respectively. The hatched boxes represent thresholds $\mathbf{C}_{\mathbf{y y}}$ (upper panel) and $\mathbf{C}_{\mathbf{y x}}$ (lower panel). Order perception is possible only if the interval between the arrivals of the sensory messages is greater than the threshold value. Perceived simultaneity results if this interval is smaller than the threshold value. Thresholds $\left(C_{x y}\right.$ vs. $\left.C_{y z}\right)$ may depend on the arrival order of the sensory messages. Upper panel: Sensory sigmal $m_{\mathbf{x}}$ arrives at the central mechanism before $m_{\mathbf{y}}$. Perceived simultaneity is produced as the arrival-time difference is smaller than threshold $C_{x y}$. Lower panel: Perceived order " $S_{y}$ precedes $S_{\mathbf{z}}$ " results as arrival-time difference is greater than threshold $\mathbf{C}_{\mathbf{y x}}$.
Assumption 2. Now assume that $m_{\mathrm{y}}$ arrives first, that is, $\mathbf{A}_{\mathbf{x}}>\mathbf{A}_{\mathbf{y}}$ (see Figure 3, lower panel). As before, if the interval between the two arrivals is smaller than threshold value $C_{y x}\left(0 \leq C_{y x}\right)$, then the arrival order cannot be registered and response $s i$ results. Otherwise, if $A_{x}>A_{y}+C_{y x}$, then the arrival order of $m_{x}$ and $m_{y}$ is registered and response $y x$ results.

Thresholds $\mathbf{C}_{\mathrm{xy}}$ and $\mathbf{C}_{\mathbf{y x}}$ may vary from trial to trial. Hence $\mathbf{C}_{\mathbf{x y}}$ and $\mathbf{C}_{\mathbf{y x}}$ are treated as random variables, each having its own distribution. (The case that both thresholds are constants is automatically included.)

One may conceive the thresholds $\mathbf{C}_{x y}$ and $\mathbf{C}_{\mathbf{y x}}$ as refractory periods of a central order-decision mechanism. If the two sensory messages arrive in fast succession, this mechanism cannot disentangle their arrival order. Specific threshold models (see below) make explicit assumptions as to how this limited time resolution might be produced by the central mechanism. It will be shown that all of these specific models differ only with regard to the distributions of the thresholds $\mathbf{C}_{\mathbf{x y}}$ and $\mathbf{C}_{\mathbf{y x}}$.

\section{Remark on the Derivations to Come}

The more general a theory, the smaller its number of testable consequences (cf. Bunge, 1983, p. 30; Coombs, 1984). Because of this tradeoff between generality and testability, only a few testable consequences can be derived from the general threshold model. Hence most of the following testable derivations are based on more specific threshold models. Nonetheless, the general threshold model provides a useful framework to work out the similarity of alternative models.

\section{Remark on Terminology}

In this paper the term threshold model has a broader meaning than in the TOJ literature (e.g., Allan, 1975a; Sternberg et al., 1975). A clarification of the different usages is necessary to avoid confusion. According to Allan (1975a, p. 32), a threshold decision model assumes that the observer bases his/her decisions on the value of the arrival time difference $\mathbf{A}_{\mathbf{x}}-\mathbf{A}_{\mathbf{y}}$ on each trial. There is an interval centered around $\mathbf{A}_{\mathbf{x}}-\mathbf{A}_{\mathbf{y}}=\mathbf{0}$ within which different values of $\mathbf{A}_{\mathbf{x}}-\mathbf{A}_{\mathbf{y}}$ cannot be discriminated. Let $\left[c_{1}, c_{2}\right]$ denote this interval, where $c_{1}$ and $c_{2}$ are fixed values on the $\mathbf{A}_{\mathbf{x}}-\mathbf{A}_{\mathbf{y}}$ axis with $c_{1}<0<c_{2}$. As the observer is required to make one of three responses $(x y, y x$, or $s i$ ), he/she responds with $x y$ if $\mathbf{A}_{\mathbf{x}}-\mathbf{A}_{\mathbf{y}} \leq c_{1}$, with $y x$ if $\mathbf{A}_{\mathrm{x}}-\mathbf{A}_{\mathrm{y}} \geq c_{2}$, and with si if $c_{1}<\mathbf{A}_{\mathrm{x}}-\mathbf{A}_{\mathrm{y}}<c_{2}$. In my terminology, Allan's model is a specific threshold model, because it can be derived from the general threshold model with the two additional assumptions $\mathbf{C}_{\mathrm{xy}}=\left|c_{1}\right|$ and $\mathbf{C}_{\mathrm{yx}}=c_{2}$. Generally, if we let $G=\left\{A_{1}, A_{2}\right\}$ be the above assumptions of the general threshold model, then a specific threshold model $M_{\mathrm{i}}$ is defined as the union of the sets $G$ and $\left\{A_{1 \mathrm{i}}, \ldots, A_{\mathrm{ni}}\right\}$, where the latter set contains $n$ additional assumptions for $M_{\mathrm{i}}$ with $n \geq 1$. According to this definition, a TOJ model is called a specific threshold model if it contains $G$ as a proper subset. Thus Allan's model is a specific threshold model, because it 
contains $G$ as a proper subset. An extreme example is the attention-switching model (discussed below): As will be evident later, this model is also a specific threshold model, because it contains $G$ as a proper subset.

\section{General Predictions}

We now turn to the basic predictions regarding the functions $Y_{L}$ and $Y_{R}$, which must hold for each specific threshold model. The main prediction is summarized in Theorem 1.

THeorem 1. Define the sums $\mathrm{D}_{\mathrm{R}} \equiv \mathrm{U}+\mathrm{C}_{\mathrm{xy}}$ and $\mathbf{D}_{\mathrm{L}} \equiv \mathbf{U}-\mathbf{C}_{\mathbf{y x}}$, where $\mathbf{U}=\mathbf{L}_{\mathrm{x}}-\mathbf{L}_{\mathbf{y}}$ denotes the arrivallatency difference. If the distributions of the random variables $\mathrm{D}_{\mathrm{L}}$ and $\mathrm{D}_{\mathrm{R}}$ do not depend on time difference d, then $Y_{\mathrm{L}}$ and $Y_{\mathrm{R}}$ can be conceived as cumulative distribution functions (CDFs) of $\mathbf{D}_{\mathrm{L}}$ and $\mathbf{D}_{\mathrm{R}}$, respectively:

$$
\begin{aligned}
& Y_{\mathrm{R}}(d) \equiv \operatorname{Pr}\left\{\mathrm{D}_{\mathrm{R}} \leq d\right\} \\
& Y_{\mathrm{L}}(d) \equiv \operatorname{Pr}\left\{\mathrm{D}_{\mathrm{L}} \leq d\right\} .
\end{aligned}
$$

(The proof of Theorem 1 is contained in Appendix A.)

This simple but powerful result forms the basis of all further considerations. Two testable properties for threshold models follow from Theorem 1.

Monotonicity property. $Y_{R}$ and $Y_{L}$ must be nondecreasing functions of $d$, as both functions can be conceived as CDFs of the random variables $D_{R}$ and $D_{L}$, respectively, which vary along the $d$-axis. This property requires that the distributions of the sums $U+C_{x y}$ and $\mathrm{U}-\mathbf{C}_{\mathrm{yx}}$ do not depend on time difference $d$. All existing specific threshold models satisfy this shape-invariance assumption. Note that this property must hold whether or not $\mathbf{U}, \mathbf{C}_{\mathrm{xy}}$, and $\mathbf{C}_{\mathbf{y x}}$ are correlated.

Dominance property. As the mean $\mathrm{E}\left(\mathbf{D}_{\mathrm{R}}\right)=\mathrm{E}(\mathrm{U})+$ $E\left(C_{x y}\right)$ of $D_{R}$ must be greater than the mean $E\left(D_{L}\right)=$ $E(U)-E\left(C_{y x}\right)$ of $D_{L}$, the function $Y_{L}$ must be displaced more to the left-hand side and the $Y_{R}$ more to the righthand side on the $d$-axis. One might therefore intuitively assume that $Y_{L}$ and $Y_{R}$ should not cross. However, this need not be true. For example, if the variance of $C_{x y}$ is large compared with the variance of $\mathbf{C}_{\mathbf{y x}}$, then it may happen that $Y_{L}$ and $Y_{R}$ intersect. Nevertheless, several models (discussed below) predict that such an intersection cannot occur. These models can be characterized by an additional assumption:

Corollary 1. (a) If thresholds $\mathbf{C}_{\mathrm{xy}}$ and $\mathbf{C}_{\mathrm{yx}}$ do not differ, that is, $\mathbf{C}_{\mathbf{x y}}=\mathbf{C}_{\mathbf{y x}}=\mathbf{C}$, and (b) if the bivariate distribution of $\mathrm{C}$ and $\mathrm{U}$ does not vary with time difference $d$, then the following dominance property must hold for each value of $d$ :

$$
Y_{\mathbf{L}}(d) \geq Y_{\mathbf{R}}(d) \text {. }
$$

Note that condition (b) is automatically satisfied if $\mathbf{U}$ and $\mathbf{C}$ are stochastically independent. (The proof of Equation 2 is contained in Appendix B.)

For the data shown in Figures 1 and 2, the dominance property is satisfied in each case but the monotonicity property is not. However, in small samples, random variability may produce nonmonotonous shapes of $Y_{R}$ and $Y_{L}$ even if threshold models are true. Therefore, one should not overvalue this violation at the present stage until more empirical evidence is available.

\section{PREDICTIONS OF SPECIFIC THRESHOLD MODELS}

In this section, specific threshold models (triggeredmoment models, perceptual-moment models, and attentionswitching models) of TOJs are discussed. It is shown that each model can be viewed as a special case of the general threshold model. The distributions of $\mathbf{C}_{\mathbf{x y}}$ and $\mathbf{C}_{\mathbf{y x}}$ are derived for each specific model. These distributions constrain the relationship of the functions $Y_{L}$ and $Y_{R}$, and hence provide useful empirical tests for these specific models.

\section{Triggered-Moment Models}

Triggered-moment models assume that the central arrival of the first sensory message triggers a moment of duration $\mathbf{C}(\mathbf{C}>0)$. This assumption may be viewed as a special case in which $\mathbf{C}_{\mathbf{x y}}=\mathbf{C}_{\mathrm{yx}}=\mathbf{C}$. If the second arrival occurs within this moment, then the arrival order cannot be detected and perceived simultaneity results (Efron, 1967; Pöppel, 1970; Sternberg \& Knoll, 1973, Section IC, Model 3; Venables, 1960). If $\left|\mathbf{A}_{\mathbf{x}}-\mathbf{A}_{\mathbf{y}}\right|>\mathbf{C}$, the arrival order is detected and the corresponding response ( $y x$ or $x y$ ) is elicited; however, if $\left|\mathbf{A}_{\mathbf{x}}-\mathbf{A}_{\mathbf{y}}\right| \leq \mathbf{C}$, no discrimination is possible and response si results.

It is usually assumed that $\mathbf{C}$ does not fluctuate from trial to trial (e.g., Baron, 1971). In the following section, this restriction is abolished and $\mathbf{C}$ is treated as a random variable that is independent of arrival-latency difference $\mathbf{U}$. The special case, that $\mathbf{C}$ is a constant, is considered in a subsequent section.

Predictions if $C$ is a random variable. As $C$ does not depend on arrival order, we have $\mathbf{D}_{\mathbf{R}}=\mathbf{U}+\mathbf{C}$ and $\mathbf{D}_{\mathbf{L}}$ $=\mathbf{U}-\mathbf{C}$. This leads immediately to four predictions: (1) The two random variables $D_{R}$ and $D_{L}$ must have the same variance, as

$$
\begin{aligned}
& \operatorname{var}\left(\mathbf{D}_{\mathbf{R}}\right)=\operatorname{var}(\mathbf{U}+\mathbf{C})=\operatorname{var}(\mathbf{U})+\operatorname{var}(\mathbf{C}) \\
& \operatorname{var}\left(\mathbf{D}_{\mathbf{L}}\right)=\operatorname{var}(\mathbf{U}-\mathbf{C})=\operatorname{var}(\mathbf{U})+\operatorname{var}(\mathbf{C}) .
\end{aligned}
$$

Consequently, $Y_{L}$ and $Y_{R}$ should have the same dispersion. $^{3}$ (2) The third central moment $E\left\{[C-E(C)]^{3}\right\}$ of $\mathrm{C}$ mediates the relationship between the third central moments of $D_{\mathbf{L}}$ and $D_{\mathbf{R}}$ :

$$
\begin{aligned}
\mathrm{E}\left\{\left[\mathrm{D}_{\mathbf{R}}-\mathrm{E}\left(\mathrm{D}_{\mathbf{R}}\right)\right]^{3}\right\}= & 2 \mathrm{E}\left\{[\mathrm{C}-\mathrm{E}(\mathrm{C})]^{3}\right\} \\
& +\mathrm{E}\left\{\left[\mathrm{D}_{\mathbf{L}}-\mathrm{E}\left(\mathrm{D}_{\mathbf{L}}\right)\right]^{3}\right\} .
\end{aligned}
$$

(Proof of Equation 3 is contained in Appendix C.) From Equation 3 it follows that $E\left\{\left[D_{R}-E\left(D_{R}\right)\right]^{3}\right\}>$ $E\left\{\left[D_{L}-E\left(D_{L}\right)\right]^{3}\right\}$ must hold if the distribution of $C$ is skewed to the right, that is, if $\mathbf{C}$ has a positive third moment. The inequality sign must be reversed if the distri- 
bution of $\mathbf{C}$ is skewed to the left, that is, if $\mathbf{C}$ has a negative third moment. Hence the skewness relationship of $Y_{L}$ and $Y_{R}$ sheds light on the unobservable distribution of $\mathbf{C}$, that is, whether this distribution is skewed to the left or to the right. As latency distributions are usually skewed to the right, one should expect that $E\left\{\left[D_{R}-E\left(D_{R}\right)\right]^{3}\right\}>E\left\{\left[D_{L}-E\left(D_{L}\right)\right]^{3}\right\}$ holds. (3) If $C$ has a symmetrical distribution, then $Y_{R}$ and $Y_{L}$ must have identical shapes. That is, $Y_{R}$ and $Y_{L}$ must be parallel functions differing only by horizontal translation. This follows as the distributions of the sums $\mathrm{U}+\mathrm{C}$ and $\mathrm{U}-\mathrm{C}$ must have identical shapes as long as $\mathbf{C}$ has a symmetrical distribution. (4) The difference $E\left(D_{R}\right)-E\left(D_{L}\right)=2 \cdot E(C)$ does not depend on perceptual latencies. This property also holds if the means $E\left(C_{x y}\right)$ and $E\left(C_{y x}\right)$ differ. In this case one obtains $E\left(D_{R}\right)-E\left(D_{1}\right)=E\left(C_{x y}\right)+E\left(C_{y x}\right)$.

Predictions if $\mathbf{C}$ is constant. If $\mathbf{C}$ is a constant, say $\mathrm{C}=c(c>0)$, then the variability of $\mathrm{D}_{\mathrm{L}}=\mathrm{U}-c$ and $\mathbf{D}_{\mathbf{R}}=\mathbf{U}+c$ is solely determined by arrival-time difference $U$. Therefore, $D_{L}$ and $D_{R}$ must have identical distributions but different means. Consequently, $Y_{R}$ and $Y_{L}$ should be parallel functions coinciding only by horizontal translation along the $d$-axis; the distance would be $2 c$. This prediction was used by Allan (1975a) and by Sternberg et al. (1975, Section 6) to test perceptual-latency models.

\section{Perceptual-Moment Hypothesis}

More than 100 years ago the biologist Karl Ernst von Baer (1862) introduced the concept of the perceptual moment, which was reactivated by Stroud (1955) as a hypothesis about the structure of psychological time. Since Stroud's work, the perceptual-moment hypothesis has had a considerable influence on psychology (see Breitmeyer, 1984; Fraisse, 1978, 1984; Neumann, 1984; Pöppel, 1978; Uttal, 1981).

This hypothesis postulates that the psychological time scale is not continuous but is partitioned into disjunctive equal intervals (moments), and that two arrivals of sensory messages can be ordered only if they fall in different moments. If the two arrivals occur during the same moment, then perceived simultaneity results. The generation of moments is thought to be independent of the time of occurrence of an external signal (Harter, 1967; Kristofferson, 1967a; Stroud, 1955).

It is usually assumed that each moment has the same duration. I abolish this assumption and treat the moment duration as a nonnegative random variable $M$ with $C D F$ $F_{M}$; that is, the psychological time scale is conceived as a sequence of intervals that differ in length. The length of an interval is distributed according to CDF $F_{M}$, and its length is uncorrelated with the lengths of the preceding intervals. (Constant moment durations are automatically included as a special case.)

Predictions if $M$ is a random variable. Assume that the first sensory message arrives during moment $i$. Now let $\mathbf{R}$ be the time (residual-moment duration) measured from the arrival of the first sensory message to the end of the current moment $i$. The arrival of $m_{\mathrm{x}}$ and $m_{\mathrm{y}}$ is detected if $\left|\mathbf{A}_{\mathbf{x}}-\mathbf{A}_{\mathbf{y}}\right|>\mathbf{R}$; otherwise, if $\left|\mathbf{A}_{\mathbf{x}}-\mathbf{A}_{\mathbf{y}}\right| \leq \mathbf{R}$, perceived simultaneity is produced and response si results. Hence, analogously to triggered-moment models, one obtains $\mathbf{D}_{\mathbf{L}}=\mathbf{U}-\mathbf{R}$ and $\mathbf{D}_{\mathbf{R}}=\mathbf{U}+\mathbf{R}$, implying again that $\operatorname{var}\left(D_{L}\right)=\operatorname{var}\left(D_{R}\right)$. Consequently, $Y_{L}$ and $Y_{R}$ should reflect the same dispersion.

An interesting further prediction regarding the skewness relationship of $Y_{L}$ and $Y_{R}$ derives from a distributional property of $\mathbf{R}$. It is known from renewal theory (see Cox \& Isham, 1980, pp. 8-9) that the density $f_{\mathbf{R}}$ of $\mathbf{R}$ is given by

$$
f_{\mathbf{R}}(t)=\left[1-F_{\mathbf{M}}(t)\right] / \mathrm{E}(\mathbf{M}),
$$

where $F_{M}$ and $\mathrm{E}(\mathrm{M})$ denote the $\mathrm{CDF}$ and the mean of $\mathbf{M}$, respectively. Note that $F_{M}$ is a nondecreasing function of $t$. Consequently, $f_{\mathrm{R}}$ must be a nonincreasing function of $t$; that is, $f_{\mathrm{R}}$ is $\mathrm{J}$-shaped with a unique mode at $t=0$. As a J-shaped distribution is skewed to the right, the third central moment of $\mathbf{R}$ must be positive. Therefore, one obtains from Equation 3 the following testable skewness relationship:

$$
\mathrm{E}\left\{\left[\mathrm{D}_{\mathrm{R}}-\mathrm{E}\left(\mathrm{D}_{\mathbf{R}}\right)\right]^{3}\right\}>\mathrm{E}\left\{\left[\mathrm{D}_{\mathrm{L}}-\mathrm{E}\left(\mathrm{D}_{\mathbf{L}}\right)\right]^{3}\right\} .
$$

This prediction must hold for each distribution of the moment duration.

Finally, the difference $E\left(D_{R}\right)-E\left(D_{R}\right)=2 \cdot E(R)$ is independent of any sensory component.

Predictions if $M$ is constant. If $M$ is a constant, say $m$, then $R$ is uniformly distributed over the interval $[0, m)$. Both sums, $D_{\mathbf{L}}=\mathbf{U}-\mathbf{R}$ and $\mathbf{D}_{\mathbf{R}}=\mathbf{U}+\mathbf{R}$, must have identical shapes, because $\mathbf{R}$ has a symmetrical distribution. Consequently, $Y_{L}$ and $Y_{R}$ should have identical shapes but different locations.

Remark. It was assumed that the generation of moments is independent of stimulus input. However, several authors (Allport, 1968; Efron \& Lee, 1971; Harter \& White, 1967; Latour, 1967; Pöppel, 1970) assume that the moments can become synchronized with stimulus input. As noted by Pöppel (1970), this synchronization could arise in at least two different ways: (1) An incoming stimulus may trigger an oscillatory central response that generates a sequence of "processing periods" (Efron, 1967), that is, a sequence of moments. (2) Alternatively, a stimulus may reset rather than initiate this oscillatory response (Latour, 1967). The present approach cannot distinguish empirically between these two interpretations. However, the above predictions of the triggered-moment model can be applied to both interpretations.

\section{Attention-Switching Models}

The attention-switching model was originally formulated within the framework of Kristofferson's (1967a, 1967b) time quantum theory and was elaborated by Allan and Kristofferson (1974) and by Allan (1975a). The attention-switching model applies to pairs of stimuli that cannot be simultaneously attended at one time. 
Assumptions. The basic assumptions may be summarized as follows:

1. Attention can be directed to channel $x$ only or to channel $y$ only but not to both simultaneously. Before the first sensory message arrives, attention is directed to channel $x(y)$ with probability $p_{\mathrm{x}}\left(p_{\mathrm{y}}=1-p_{\mathrm{x}}\right)$.

2. An internal timing mechanism generates a sequence of time points. Only at these time points can attentional switches from one channel to another be accomplished. The generation of time points is independent of stimulus input. The interval between two successive time points represents a nonnegative random variable $\mathbf{Q}$-called time quantum. (The above authors assume $\mathbf{Q}$ to be a constant, $q$; this case is automatically included in the following analysis.)

3. The arrival of a sensory message in either an unattended or an attended channel triggers attentional switches until all sensory messages are registered.

4. A sensory message is registered only when it has arrived and attention is directed to its channel. To detect the arrival order of $m_{\mathrm{y}}$ and $m_{\mathrm{x}}$ it is necessary to register the arrival of one sensory message, switch attention to the channel of the second, and then register the arrival of the second sensory message. If the second arrival has already occurred before an attentional switch to its channel, then perceived simultaneity is produced and response $s i$ is elicited.

Distributions of $\mathbf{C}_{x y}$ and $C_{y x}$. Let $R$ be the time measured from the arrival of the first sensory message to the time point when attention is directed to the initially unattended channel, that is, the residual time of $\mathbf{Q}$. First it is assumed that $m_{\mathrm{x}}$ arrives before $m_{\mathrm{y}}$. Then the density $f_{C_{x y}}$ of $C_{x y}$ is easily obtained if one takes into account the initial state of attention: If attention is initially directed to channel $x$, then $\mathbf{C}_{\mathrm{xy}}$ corresponds to the distribution of $\mathbf{R}$; however, if it is initially directed to channel $y$, then $\mathbf{C}_{\mathbf{x y}}$ corresponds to the distribution of the sum $\mathbf{R}+\mathbf{Q}$. Therefore, $f_{\mathrm{C}_{\mathbf{x y}}}$ represents a mixture distribution produced by sampling probabilistically from the two basis distributions $f_{\mathrm{R}}$ and $f_{\mathrm{R}+Q}$ with probabilities $p_{\mathrm{x}}$ and $1-p_{\mathrm{x}}$, respectively:

$$
f_{\mathrm{C}_{\mathrm{xy}}}(t)=p_{\mathrm{x}} \cdot f_{\mathrm{R}}(t)+\left(1-p_{\mathrm{x}}\right) \cdot f_{\mathrm{R}+\mathrm{Q}}(t) .
$$

An analogous reasoning leads to the distribution of $f_{\mathrm{C}_{\mathrm{yx}}}$ of $\mathbf{C}_{\mathbf{y x}}$ :

$$
f_{\mathrm{C}_{\mathrm{yx}}}(t)=\left(1-p_{\mathrm{x}}\right) \cdot f_{\mathrm{R}}(t)+p_{\mathrm{x}} \cdot f_{\mathrm{R}+\mathrm{Q}}(t) .
$$

Predictions if $Q$ is a random variable. From Equation 4 it is easily seen that the distributions of $\mathbf{C}_{\mathbf{x y}}$ and $\mathbf{C}_{y x}$ are identical if attention is initially directed to channel $x$ or channel $y$ with equal probabilities, that is, if $p_{\mathrm{x}}=p_{\mathrm{y}}=0.5$. In this case the variances of $\mathbf{C}_{\mathrm{xy}}$ and $\mathbf{C}_{\mathrm{yx}}$ would be equal and therefore $\operatorname{var}\left(D_{L}\right)=\operatorname{var}\left(D_{R}\right)$. However, the distributions of $D_{L}$ and $D_{R}$ may differ extremely if $p_{\mathrm{x}}$ and $p_{\mathrm{y}}$ are unequal. Without making specific supplementary assumptions about the distribution of $\mathbf{Q}$, no constraining relationships of the functions $Y_{\mathrm{L}}$ and $Y_{\mathrm{R}}$ are obvious.

However, a quite general distribution-free prediction is available if one considers the difference $E\left(D_{R}\right)-E\left(D_{L}\right)$. It is shown in Appendix D that this difference does not depend on perceptual latencies or on $p_{\mathbf{x}}$ :

$$
\mathrm{E}\left(\mathbf{D}_{\mathbf{R}}\right)-\mathrm{E}\left(\mathbf{D}_{\mathbf{L}}\right)=2 \cdot \mathrm{E}(\mathbf{R})+\mathrm{E}(\mathbf{Q}) \text {. }
$$

Therefore, if one proceeds from attentional-switching models, $E\left(D_{R}\right)-E\left(D_{L}\right)$ should remain constant if the intensities of the stimuli $S_{\mathrm{x}}$ and $S_{\mathrm{y}}$ are varied or if attentional demands are varied experimentally. Such a test requires only that $\mathbf{U}$ and $\mathbf{Q}$ be independent in mean (see Sternberg, 1969).

Predictions if $\mathbf{Q}$ is constant. Assume that $\mathbf{Q}$ is a nonnegative constant, say $q$ (Allan, 1975a; Allan \& Kristofferson, 1974; Kristofferson, 1967a, 1967b). In this case $\mathbf{R}$ would be uniformly distributed over the interval $[0, q)$ and the sum $\mathbf{R}+\mathbf{Q}$ uniformly over the interval $[q, 2 \cdot q)$. Therefore the densities $f_{\mathrm{C}_{\mathrm{yx}}}$ and $f_{\mathrm{C}_{\mathrm{xy}}}$ correspond to mixture distributions of these two rectangular distributions (Figure 4).

It can be seen in Figure 4 that the distribution of $\mathbf{C}_{\mathbf{x y}}$ must always be the reflection of the distribution of $\mathbf{C}_{\mathbf{y x}}$, irrespective of probability $p_{\mathrm{x}}$. Thus the relation

$$
\begin{aligned}
\operatorname{Pr}\left\{\mathbf{C}_{\mathrm{yx}} \leq t\right\} & =\operatorname{Pr}\left\{\mathbf{C}_{\mathrm{xy}} \geq 2 \cdot q-t\right\} \\
& =\operatorname{Pr}\left\{2 \cdot q-\mathbf{C}_{\mathrm{xy}} \leq t\right\}
\end{aligned}
$$

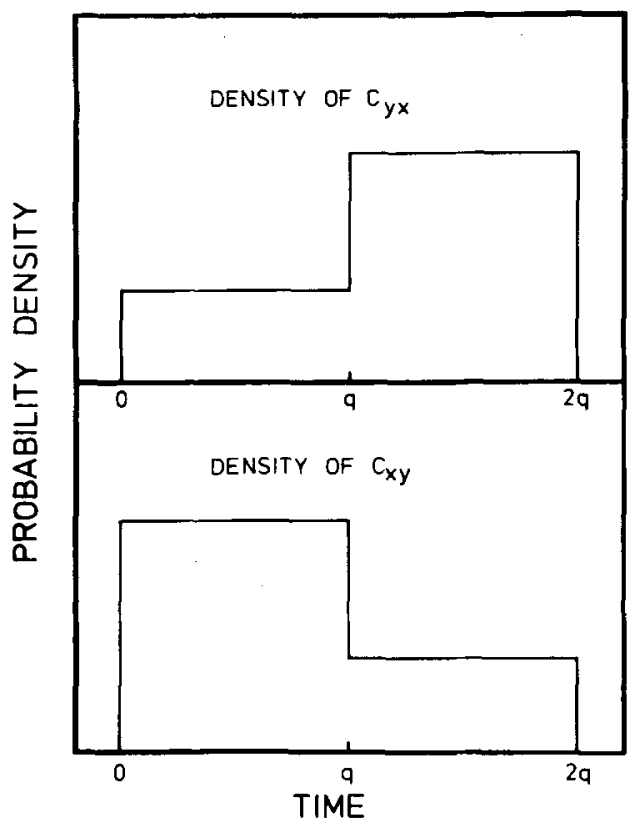

Figure 4. Probability density of $C_{y x}$ (upper panel) and of $C_{x y}$ (lower panel), assuming a constant time quantum $q$ and $p_{x}>p_{y}$. Note that the density of $C_{y x}$ corresponds to the reflection of the density of $C_{x y}$. Therefore the equation $\operatorname{Pr}\left\{C_{y x} \leq t\right\}=\operatorname{Pr}\left\{C_{x y} \geq 2 q-t\right\}$ must hold for each value $t$ in the interval $[0,2 q)$ and for each value of $p_{x}$. 
must hold, and hence one may conceive the two random variables $\mathbf{C}_{\mathbf{y x}}$ and $\mathbf{C}_{\mathrm{yx}}^{*}=2 \cdot q-C_{\mathrm{xy}}$ as being equivalent; that is, $\mathbf{C}_{\mathbf{y x}}$ and $\mathbf{C}_{\mathbf{y}}^{*}$ have identical distributions.

Now, the sum $D_{\mathrm{L}}=\mathrm{U}-\mathbf{C}_{\mathrm{yx}}$ can be rearranged as follows:

$$
\begin{aligned}
\mathbf{D}_{\mathbf{L}} & =\mathbf{U}-\mathbf{C}_{\mathbf{y x}} \\
& =\mathbf{U}-\mathbf{C}_{\mathbf{y x}}^{*} \\
& =\mathbf{U}-\left(2 \cdot q-\mathbf{C}_{\mathbf{x y}}\right) \\
& =\mathbf{U}+\mathbf{C}_{\mathbf{x y}}-2 \cdot \boldsymbol{q} \\
& =\mathbf{D}_{\mathbf{R}}-2 \cdot q .
\end{aligned}
$$

The last expression shows that the shapes of the distributions of $D_{L}$ and $D_{R}$ must be identical: $D_{\mathrm{L}}$ is shifted by the distance $2 \cdot q$ to the left, relative to $D_{R}$. Consequently, $Y_{L}$ and $Y_{R}$ must be parallel functions.

\section{Remarks on the Predictions}

Almost all tests discussed so far constrain the relationship of the functions $Y_{R}$ and $Y_{L}$. It should be emphasized that these tests do not depend on the distribution of arrivallatency difference $\mathbf{U}$. Therefore, no ancillary assumptions about perceptual latencies-assumptions about latency distributions-are needed to apply these tests. This demonstrates the advantage of the ternary-response-task approach over the traditional one.

Sternberg and Knoll (1973) showed for the traditional approach that order-decision components cannot be separated from perceptual latencies without making additional specific assumptions about $L_{x}$ and $L_{y}$. Some authors have assumed that the latencies have no trial-to-trial variability. For example, Baron's (1971) rejection of the perceptual-moment model was based on this ancillary assumption. However, a rejection of such a strong model need not invalidate its basic concept: It is possible that the ancillary assumption was wrong and therefore produced the rejection (for a similar argument, see Vorberg, 1985). In sum, the present approach enables more direct tests of the various concepts of the central order-decision components. Moreover, it is possible to isolate effects of the central-order mechanism by determining the difference $E\left(D_{R}\right)-E\left(D_{L}\right)$ without making ancillary assumptions regarding the perceptual latencies.

\section{THRESHOLD MODELS AND CONFIDENCE-RATING DATA}

Although we investigated the predictions of threshold models within the ternary-response task, our analysis can be extended to confidence-rating tasks. In this section I investigate the predictions of the general threshold model for Allan's (1975b) confidence-rating data and Allan's (1975a) successiveness/order data.

Allan (1975b) reported data from a TOJ task in which the subject was required to rate his/her confidence about his/her order response in each trial. There were four response categories: (1) certain that $S_{\mathrm{x}}$ appeared before $S_{\mathrm{y}}$ (response: $x y_{\mathrm{C}}$ ); (2) certain that $S_{\mathrm{y}}$ appeared before $S_{\mathrm{x}}$ (response: $y x_{\mathrm{C}}$ ); (3) uncertain that $S_{\mathrm{x}}$ appeared before $S_{\mathrm{y}}$ (response: $x y_{y}$ ); and (4) uncertain that $S_{y}$ appeared before $S_{\mathrm{x}}$ (response: $y x_{\mathrm{U}}$ ). Let $\operatorname{Pr}\left\{x y_{\mathrm{C}} \mid d\right\}, \operatorname{Pr}\left\{y x_{\mathrm{C}} \mid d\right\}$, $\operatorname{Pr}\left\{x y_{U} \mid d\right\}$, and $\operatorname{Pr}\left\{y x_{U} \mid d\right\}$ be the corresponding response probabilities of $x y_{\mathrm{C}}, y x_{\mathrm{C}}, x y_{\mathrm{U}}$, and $y x_{\mathrm{U}}$, respectively, measured at time difference $d$. Allan (1975b) used these response probabilities to generate the following family of psychometric functions: $Y_{L}(d) \equiv 1$ $\operatorname{Pr}\left\{y x_{C} \mid d\right\}, Y_{M}(d) \equiv \operatorname{Pr}\left\{x y_{C} \mid d\right\}+\operatorname{Pr}\left\{x y_{U} \mid d\right\}$, and $\mathbf{Y}_{\mathbf{R}}(d) \equiv \operatorname{Pr}\left\{x y_{C} \mid d\right\}$.

Allan (1975a) reported similar data under the successiveness/order condition of her experiment. Subjects made a successiveness decision followed by an order decision on each trial. They judged whether $S_{\mathrm{x}}$ and $S_{\mathrm{y}}$ were successive (response: $S U$ ) or simultaneous (response: $S I$ ) and then whether $S_{\mathrm{x}}$ preceded $S_{\mathrm{y}}$ (response: $x y$ ) or whether $S_{\mathrm{y}}$ preceded $S_{\mathrm{x}}$ (response: $y x$ ). Thus there were four response categories: $x y_{\mathrm{SU}}, y x_{\mathrm{SU}}, x y_{\mathrm{SI}}$, and $y x_{\mathrm{SI}}$. Because time difference $d$ was varied, three psychometric functions $-Y_{\mathrm{L}}(d) \equiv 1-\operatorname{Pr}\left\{y x_{\mathrm{Su}} \mid d\right\}, Y_{\mathrm{M}}(d) \equiv$ $\operatorname{Pr}\left\{x y_{\mathrm{Su}} \mid d\right\}+\operatorname{Pr}\left\{x y_{\mathrm{SI}} \mid d\right\}$, and $Y_{\mathrm{R}}(d) \equiv \operatorname{Pr}\left\{x y_{\mathrm{su}} \mid d\right\}$ were generated $\left(Y_{L}\right.$ and $Y_{R}$ are shown in Figure 1). This set of functions is remarkably similar to the set generated by the confidence-rating task.

I will show below how the general threshold can be applied to such data.

\section{Response Mapping}

According to threshold models, the central arrival order of $m_{\mathrm{x}}$ and $m_{\mathrm{y}}$ is either registered (perceived order is produced) or not (perceived simultaneity is produced). Thus threshold models assume that one of the following perceptual states is produced on each trial: $S_{x}$ precedes $S_{y}, S_{y}$ precedes $S_{x}$, and $S_{y}$ and $S_{x}$ are simultaneous. As the perceptual states do not directly correspond to the response categories in Allan's (1975a, 1975b) studies, additional assumptions are needed about the function that carries the perceptual states to the responses. I adopt the response mapping proposed by Allan (1975a, p. 32; $1975 b$, p. 371) and by Sternberg et al. (1975, p. 13): If state $S_{x}$ precedes $S_{y}$ is produced, the observer responds with $x y_{\mathrm{c}}\left(x y_{\mathrm{su}}\right)$; if state $S_{y}$ precedes $S_{x}$ is produced, the observer responds with $y x_{\mathrm{c}}\left(y x_{\mathrm{su}}\right)$; if state $S_{y}$ and $S_{x}$ are simultaneous is produced, no order information is available and the observer makes an $x y_{\mathrm{U}}\left(x y_{\mathrm{SI}}\right)$ response with probability $\beta$ and a $y x_{U}\left(y x_{S I}\right)$ response with probability $1-\beta$.

\section{Predictions}

Theorem 2 summarizes the main result of the general threshold model for Allan's (1975a, 1975b) multifunction approach.

THEOREM 2. If the general threshold model and the above response mapping hold, then the psychometric functions $Y_{L}, Y_{M}$, and $Y_{R}$ are given by 


$$
\begin{aligned}
& \mathbf{Y}_{\mathbf{L}}(d) \equiv \operatorname{Pr}\left\{\mathbf{D}_{\mathrm{L}} \leq d\right\} \\
& \mathbf{Y}_{\mathrm{M}}(d) \equiv \operatorname{Pr}\left\{\mathbf{D}_{\mathrm{M}} \leq d\right\}=\beta \cdot \operatorname{Pr}\left\{\mathbf{D}_{\mathrm{L}} \leq d\right\}+(1-\beta) \cdot \operatorname{Pr}\left\{\mathbf{D}_{\mathrm{R}} \leq d\right\} \\
& \mathbf{Y}_{\mathrm{R}}(d) \equiv \operatorname{Pr}\left\{\mathbf{D}_{\mathrm{R}} \leq d\right\},
\end{aligned}
$$

where $\beta, \mathbf{D}_{\mathrm{L}}$, and $\mathrm{D}_{\mathrm{R}}$ are defined above. (The proof for $Y_{L}$ and $Y_{R}$ is identical to that for Theorem 1. Appendix $E$ contains the proof for $Y_{M}$.)

The results for $Y_{R}$ and $Y_{L}$ are identical with the above results for ternary TOJs: $Y_{L}$ and $Y_{R}$ are the CDFs of $D_{L}=\mathbf{U}-C_{y x}$ and $D_{R}=U+C_{x y}$, respectively. Consequently, all results regarding the relationship of $Y_{R}$ and $Y_{L}$ can be applied to Allan's (1975b) confidence-rating task and to Allan's (1975a) successiveness/order task.

Theorem 2 shows an interesting property of $Y_{M}$ : This function can be conceived as a mixture distribution $\operatorname{Pr}\left\{D_{M} \leq d\right\}$ produced from the basis distributions $\operatorname{PR}\left\{D_{L} \leq d\right\}$ and $\operatorname{Pr}\left\{D_{R} \leq d\right\}$. The relevance of this observation is straightforward because it enables several testable predictions for $Y_{M}$ :

1. Monotonicity of $Y_{M}: Y_{M}$ should be an increasing function because it can be conceived as a CDF.

2. Bounds for $Y_{M}$ : Because $Y_{M}(d)$ can be regarded as the mean of $Y_{R}(d)$ and $Y_{L}(d)$, and if the dominance property $Y_{L}(d) \geq Y_{R}(d)$ holds (see Corollary 1), it follows that the relationship $Y_{L}(d) \geq Y_{M}(d) \geq Y_{R}(d)$ must hold for all values of $d$. Allan's (1975a, 1975b) data are consistent with predictions 1 and 2.

The central moments of $\mathbf{D}_{\mathbf{M}}$ can be predicted from the central moments of $D_{L}$ and $D_{R}$. Let $\mu_{1}^{M}, \mu_{1}^{R}$, and $\mu_{1}^{L}$ denote the $i$ th central moment of $D_{M}, D_{R}$, and $D_{L}$, respectively. From the axioms of conditional probability theory, one obtains:

3. Mean of $\mathbf{D}_{\mathbf{M}}$ :

$$
\mu_{1}^{\mathrm{M}}=\beta \cdot \mu_{1}^{\mathrm{L}}+(1-\beta) \cdot \mu_{1}^{\mathrm{R}} .
$$

\section{Variance of $\mathrm{D}_{\mathrm{M}}$ :}

$$
\mu_{2}^{\mathbf{M}}=\beta \cdot \mu_{2}^{\mathbf{L}}+(1-\beta) \cdot \mu_{2}^{\mathbf{R}}+\beta(1-\beta)\left(\mu_{1}^{\mathrm{L}}-\mu_{1}^{\mathbf{R}}\right)^{2} .
$$

Derivations of $\mu_{1}^{M}$ and $\mu_{2}^{M}$ can be found in Meyer, Yantis, Osman, and Smith (1985, pp. 507-509).

5. Skewness of $\mathrm{D}_{\mathrm{M}}$ : The third central moment $\mu_{3}^{\mathrm{M}}$ is given by

$$
\begin{aligned}
\mu_{3}^{\mathrm{M}}= & \beta \cdot \mu_{3}^{\mathrm{L}}+(1-\beta) \cdot \mu_{3}^{\mathrm{R}}+\beta(1-\beta)\left(\mu_{1}^{\mathrm{L}}-\mu_{1}^{\mathrm{R}}\right) \\
& \cdot\left[3\left(\mu_{2}^{\mathrm{L}}-\mu_{2}^{\mathrm{R}}\right)(1-2 \beta)\left(\mu_{1}^{\mathrm{L}}-\mu_{1}^{\mathrm{R}}\right)^{2}\right] .
\end{aligned}
$$

This formula is derived in a manner analogous to the formula for $\boldsymbol{\mu}_{\mathbf{2}}^{\mathbf{M}}$.

Predictions 3, 4, and 5 will be tested in a later section. We shall proceed as follows: (1) The central moments of $D_{L}, D_{M}$, and $D_{R}$ can be estimated from Allan's (1975a, $1975 \mathrm{~b}$ ) data by a method introduced below. (2) An estimate for $\beta$ is provided by $\beta_{\text {est. }}=N_{x y_{U}} / N_{U}$, where $N_{x y U}$ and $\mathrm{N}_{\mathrm{U}}$ denote the total number of $x y_{\mathrm{U}}$ and uncertain responses, respectively. (3) The estimated central moments of $D_{L}$ and $D_{R}$ along with $\beta_{\text {est. }}$ are used to predict the first three central moments of $\mathbf{D}_{\mathbf{M}}$ via the equations introduced above. If predicted and observed values agree, then both the general model and the assumed response mapping would be validated.

\section{Summary of Predictions}

All predictions for ternary TOJs and confidence-rater data are briefly summarized for later reference.

1. Monotonicity property: Must hold for each threshold model.

2. Dominance property: $Y_{L}(d) \geq Y_{R}(d)$, for all values of $d$. Must hold if (1) $\mathbf{C}_{\mathbf{x y}}=\mathbf{C}_{\mathrm{yx}}=\mathbf{C}$ and (2) $\mathbf{C}$ and $\mathbf{U}$ are stochastically independent. Applies to triggeredmoment models, perceptual-moment models, all attentionswitching models with $p_{\mathrm{x}}=0.5$, all attention-switching models with a constant time quantum.

3. Equal dispersion property: $\operatorname{var}\left(\mathbf{D}_{\mathbf{L}}\right)=\operatorname{var}\left(\mathbf{D}_{\mathrm{R}}\right)$. Most hold if (1) $C_{x y}=C_{y x}=C$ and (2) $C$ and $U$ are uncorrelated. Applies to triggered-moment models, perceptual-moment models, all attention-switching models with $p_{\mathrm{x}}=0.5$, all attention-switching models with a constant time quantum.

4. Skewness property: The third central moment of $D_{R}$ must be greater than that of $D_{\mathrm{L}}$ if (1) $\mathbf{C}_{\mathrm{xy}}=\mathbf{C}_{\mathrm{yx}}=\mathbf{C}$, (2) $\mathbf{C}$ and $U$ are uncorrelated, and (3) $C$ has a positive third central moment. Applies to perceptual-moment models with a variable moment duration, triggeredmoment models.

5. Parallelism property: $Y_{\mathrm{L}}$ and $Y_{\mathrm{R}}$ should coincide by a horizontal shift of one toward the other (for a more formal definition, see Falmagne, 1985, p. 157). Applies to triggered-moment models and perceptual-moment models with a constant moment duration, attention-switching models with a constant time quantum.

6. Property of $Y_{M}$ : For Allan's (1975a, 1975b) data, $Y_{M}$ can be regarded as a mixture distribution formed from the basis distributions of $\mathbf{D}_{\mathbf{R}}$ and $\mathbf{D}_{\mathbf{L}}$. If the assumed response mapping holds, then this property must hold for all threshold models. This property enables the prediction of mean, variance, and skewness of $D_{M}$.

These predictions are tested using the data reported by Allan (1975a, 1975b) and by Benussi (1913) along with the data produced by the following experiment.

\section{EXPERIMENT}

A ternary TOJ approach was utilized for the present experiment. The two stimuli, $S_{\mathrm{x}}$ and $S_{\mathrm{y}}$, were spatially separated light flashes. The purpose of this experiment was twofold.

First, it replicated the study of Benussi (1913). This replication was necessary because Benussi (1913) reported only group averages. Averaging of individual psychometric functions can lead to several artifacts (see Section X,E in Sternberg \& Knoll, 1973). An average function may show features that are nonexistent in individual functions 
(Estes, 1956). Therefore, the data set for each subject was analyzed separately in the present study.

The second purpose was to test whether the difference $E\left(D_{R}\right)-E\left(D_{L}\right)$ would be affected by stimulus intensity. Two intensity conditions were used - the intensity of the flash pair was either high or low. If the central orderdecision process does not depend on stimulus properties, then the difference $\mathbf{E}\left(\mathbf{D}_{\mathbf{R}}\right)-\mathrm{E}\left(\mathbf{D}_{\mathrm{L}}\right)=\mathrm{E}\left(\mathbf{C}_{\mathbf{x y}}\right)+\mathrm{E}\left(\mathbf{C}_{\mathbf{y x}}\right)$ should not vary with stimulus intensity (cf. also Equation 5). This prediction must hold for perceptual-moment models, triggered-moment models, and attentionswitching models. Note that nothing has to be assumed about the dependencies among the variables $C_{x y}, C_{y x}, L_{y}$, and $\mathbf{L}_{\mathbf{x}}$ to test this prediction.

\section{Method}

Subjects. Three right-handed subjects, G.U., M.P., and U.D. (staff members of our psychology department with no known visual deficiencies), participated in the experiment. Their ages were 29 , 33, and 31 years, respectively. They were paid 8 DM (approximately $\$ 2.50$ ) for each experimental session, which lasted about $45 \mathrm{~min}$.

Apparatus. All sessions were conducted in a sound-attenuated chamber. Two yellow light-emitting diodes (OPCOA, LSM-28LA1) were located in front of the subject, who viewed the diodes from a chinrest at a distance of $60 \mathrm{~cm}$. The diodes were situated above and below a central fixation diode, which was green and was located at eye level. The distance between the top and bottom diodes was $10 \mathrm{~cm}\left(9.6^{\circ}\right.$ visual angle); both diodes were equidistant from the central fixation diode. The top and bottom diodes were $6 \mathrm{~mm}\left(0.57^{\circ}\right)$ and the fixation diode was $3 \mathrm{~mm}\left(0.25^{\circ}\right)$ in diameter. The luminosities of both the bottom and the top diode were approximately 0.50 and 8.0 mod in the low- and high-intensity conditions, respectively. For each subject and each intensity level, the bottom and top diodes were adjusted in such a way that both appeared equally intense. All intensities were above detection threshold.

The response panel consisted of one start button and three response buttons, located $5 \mathrm{~cm}$ to the left, $5 \mathrm{~cm}$ to the right, and $5 \mathrm{~cm}$ behind the start button. The left, right, and rear buttons were assigned to the three response categories "bottom first" (bt), "top and bottom simultaneously" (si), and "top first" ( $t b)$, respectively. The sequence of trial events was controlled by a microcomputer, which was situated in a different room.

Procedure. The beginning of an experimental trial was signaled by the lighting of the fixation diode. The subject started the trial by pressing the start button with his/her right hand. After a 2-sec period the first stimulus light (top or bottom diode) was illuminated. The second stimulus was illuminated after one of five possible intervals of $d(0,25,50,75$, or $100 \mathrm{msec})$. For convenience, $d$ is defined to be negative when the bottom light was presented first, and positive when the top light was presented first. Both stimulus durations were $5 \mathrm{msec}$, and the intensity of the stimulus pair was either low or high with equal probability. After each trial, the subject indicated his/her guess by pressing one of the three response buttons. As soon as the subject pressed a response button the central fixation light was terminated. After an intertrial interval of $3 \mathrm{sec}$ the fixation diode was lighted again and the subject was free to initiate the next trial.

At no time during the experiment was the subject given any information regarding his/her performance, other than verbal information related to consistency and stability.

An experimental session consisted of 240 trials with a 5-min rest after $\mathbf{1 2 0}$ trials. In half of the trials the intensity of the stimulus pair was high, whereas in the other half it was low. For each inten- sity condition and each time difference $|d|>0 \mathrm{msec}(d=0 \mathrm{msec})$ there were $10(40)$ trials; that is, $d$ was with equal probability negative, positive, or zero on each trial. Each session was preceded by a 5-min darkness-adaptation period.

All subjects received 5 practice sessions followed by 10 experimental sessions. Only 1 session per day was run for each subject.

\section{Results}

Only the data obtained in the experimental sessions were used for data analysis. For each subject and intensity condition the relative frequencies of the responses $b t, s i$, and tb are shown in Table 1. A two-sample chi-square test was used to compare the response frequencies in both intensity conditions for each subject; separate chi-squares were determined for each $d$ value, with the individual chisquare values and $d f \mathrm{~s}$ then summed (U.D.: $\chi^{2}(18)=353$, $p<.001$; M.P.: $\chi^{2}(18)=71, p<.001$; G.U.: $\chi^{2}(18)$ $=37, p<.01)$. Strong intensity effects resulted for M.P. and U.D., whereas moderate effects were obtained for G.U.

Figures 5, 6, and 7 show estimates of the functions $Y_{\mathrm{R}}(d)=\operatorname{Pr}\{t b \mid d\}$ and $Y_{\mathrm{L}}(d)=1-\operatorname{Pr}\{b t \mid d\}$ for each subject and each intensity level. These functions suggest nonmonotonous shapes - an observation that agrees with the data reported by Allan (1975a) and Benussi (1913). Again the dominance property is satisfied in each case.

An evaluation of whether the difference $E\left(D_{R}\right)-E\left(D_{L}\right)$ varied with stimulus intensity will follow after the method for estimating the moments of $D_{L}$ and $D_{R}$ has been introduced in the next section.

\section{Estimating the Moments of $D_{L}$ and $D_{R}$}

The empirical functions of $Y_{L}$ and $Y_{R}$ can be conceived as estimates of the CDFs $\operatorname{Pr}\left\{\mathrm{D}_{\mathrm{L}} \leq d\right\}$ and $\operatorname{Pr}\left\{\mathrm{D}_{\mathrm{R}} \leq d\right\}$,

Table 1

Response Proportions as a Function of Stimulus Intensity and Time Difference $d$ for Each Subject

Time Difference $d$ (msec)

\begin{tabular}{|c|c|c|c|c|c|c|c|c|c|c|}
\hline \multirow[b]{2}{*}{ Subject } & \multirow[b]{2}{*}{ Response } & \multicolumn{9}{|c|}{ Time Difference $d$ (msec) } \\
\hline & & -100 & -75 & -50 & -25 & 0 & 25 & 50 & 75 & 100 \\
\hline \multicolumn{11}{|c|}{ Part 1: High Intensity } \\
\hline \multirow[t]{3}{*}{ U.D. } & $b t$ & .99 & .89 & .61 & .50 & .28 & .24 & .11 & .06 & .03 \\
\hline & $s i$ & .00 & .01 & .08 & .23 & .27 & .20 & .04 & .02 & .00 \\
\hline & $t b$ & .01 & .10 & .31 & .27 & .45 & .55 & .85 & .92 & .97 \\
\hline \multirow[t]{3}{*}{ M.P. } & $b t$ & .98 & .91 & .62 & .43 & .22 & .27 & .26 & .21 & .10 \\
\hline & si & .00 & .01 & .26 & .42 & .64 & .51 & .22 & .05 & .01 \\
\hline & $t b$ & .02 & .08 & .12 & .15 & .14 & .22 & .52 & .74 & .89 \\
\hline \multirow[t]{3}{*}{ G.U. } & $b t$ & .99 & .98 & .73 & .25 & .08 & .11 & .15 & .15 & .03 \\
\hline & si & .00 & .00 & .19 & .70 & .88 & .82 & .29 & .01 & .00 \\
\hline & $t b$ & .01 & .02 & .08 & .05 & .04 & .07 & .56 & .84 & .97 \\
\hline
\end{tabular}

Part 2: Low Intensity

\begin{tabular}{lllllllllll} 
U.D. & $b t$ & .92 & .79 & .64 & .38 & .34 & .32 & .37 & .35 & .27 \\
& $s i$ & .06 & .10 & .27 & .53 & .50 & .47 & .36 & .25 & .18 \\
& $t b$ & .02 & .11 & .09 & .09 & .16 & .20 & .26 & .40 & .56 \\
M.P. & $b t$ & .93 & .75 & .48 & .31 & .17 & .22 & .16 & .19 & .09 \\
& $s i$ & .02 & .10 & .22 & .43 & .57 & .47 & .29 & .25 & .05 \\
& $t b$ & .05 & .14 & .30 & .26 & .26 & .30 & .55 & .56 & .86 \\
G.U. & $b t$ & .98 & .94 & .61 & .27 & .05 & .06 & .06 & .09 & .04 \\
& $s i$ & .01 & .03 & .28 & .67 & .90 & .82 & .51 & .10 & .02 \\
& $t b$ & .01 & .03 & .11 & .06 & .05 & .12 & .43 & .81 & .94 \\
\hline
\end{tabular}




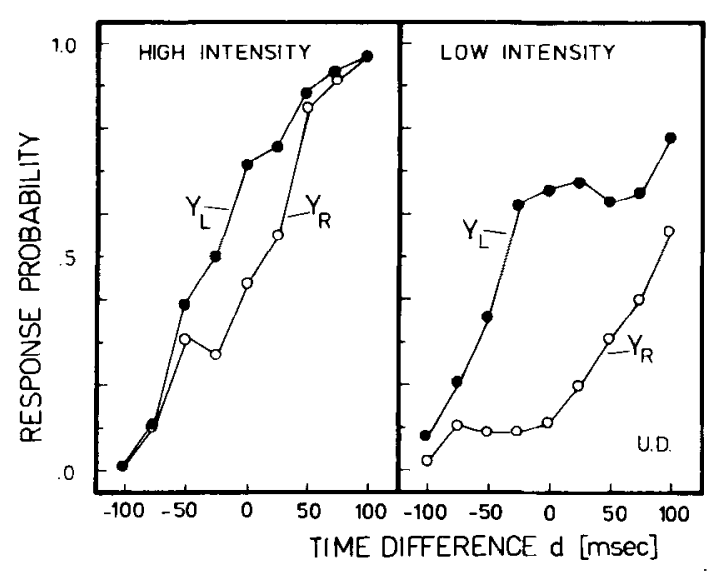

Figure 5. Results for Subject U.D.

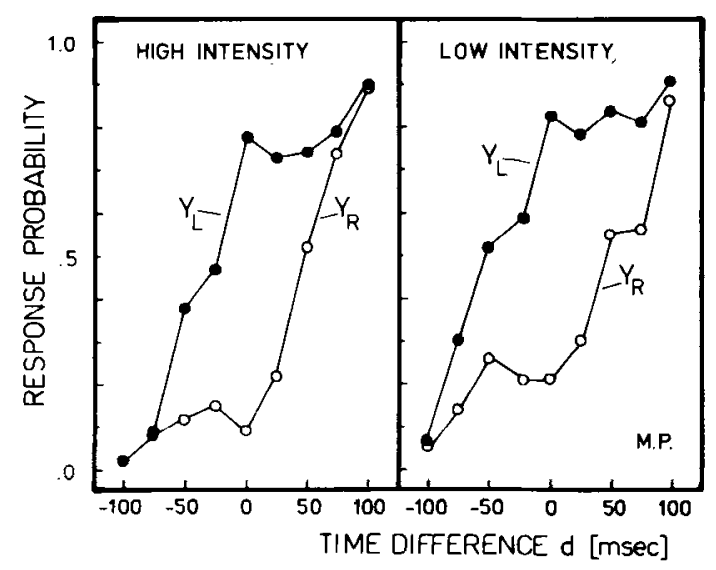

Figure 6. Results for Subject M.P.

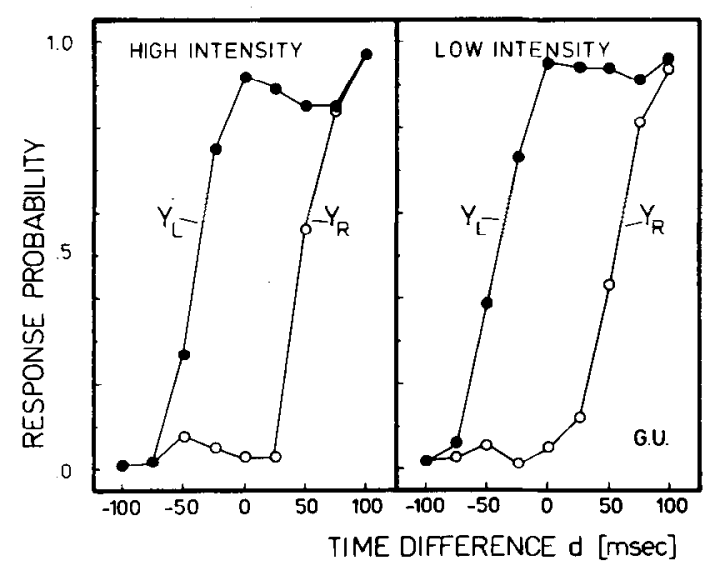

Figure 7. Results for Subject G.U. respectively. The problem is the following: How can one use this information to derive estimates of the central moments of $\mathbf{D}_{\mathrm{L}}$ and $\mathbf{D}_{\mathrm{R}}$ ?

A usual technique in psychophysics to solve this problem is to fit a smooth function from a certain parametric family of CDFs. The desired moments are then derived from the fitted function. However, the predictions developed in this paper are distribution-free; specifying a certain family of CDFs limits the conclusions to this family. Furthermore, there is at present no rationale behind choosing a particular family of CDFs. Therefore, a distribution-free approach is given preference.

The Spearman-Kärber (S-K) method (Spearman, 1908) and its elaboration (Epstein \& Churchman, 1944; Sternberg, Knoll, \& Zukofsky, 1982) provides a distributionfree solution to this problem. The S-K method treats the empirical CDF as a cumulative grouped frequency distribution from which the "original" grouped frequency distribution is reconstructed. This reconstructed grouped frequency distribution is then used to compute relatively directly the desired moments.

Recently, Sternberg et al. (1982, pp. 234-236) reported a modified S-K estimator. This estimator provides the $r$ th raw moment $m_{r}^{\prime}$ of the random variable $D$, which is assumed to underlie the function $Y$ :

$$
m_{r}^{\prime}=\sum_{i=1}^{N+1}\left(p_{i}-p_{i-1}\right) \cdot\left\{\left(d_{i}^{+1}-d_{i-1}^{i+1}\right) /\left[(r+1) \cdot\left(d_{i}-d_{i-1}\right)\right]\right\},
$$

where $p_{i}$ denotes the estimate of $Y\left(d_{i}\right), i=0, \ldots, N+1$; $\left\{d_{1}<d_{2}, \ldots,<d_{N}\right\}$ is the set of time differences used in the experiment; $d_{0}$ and $d_{N+1}$ are chosen in such a way that one can assume $Y\left(d_{0}\right)=0$ and $Y\left(d_{N+1}\right)=1 .{ }^{4}$

The function $Y$ is regarded as a CDF; consequently, it must be a nondecreasing function. As the empirical functions do occasionally violate this restriction, a monotonizing procedure was applied to the set of proportions $\left\{p_{i}: i=1, \ldots, N\right\}$ to obtain a set of nondecreasing proportions $\left\{p_{i}^{*}: i=1, \ldots, N\right.$ and $\left.p_{i}^{*} \leq p_{i+1}^{*}\right\}$. The monotonizing procedure yields a maximum-likelihood estimate of the assumed underlying CDF of $\mathbf{D}$ (see Ayer, Brunk, Ewing, Reid, \& Silverman, 1955). The set of nondecreasing proportions was used to compute the desired raw moments via Equation 6. (See also Sternberg et al., 1982.)

Finally, the raw moments $m_{1}^{\prime}, m_{2}^{\prime}$, and $m_{3}^{\prime}$ are used to estimate the mean $(M)$, the standard deviation $(S D)$, and the skewness $(S K)$ of the random variable $\mathrm{D}$ :

$$
\begin{aligned}
M & =m_{1}^{\prime} \\
S D & =\left[m_{2}^{\prime}-m_{1}^{\prime} \cdot m_{1}^{\prime}\right]^{1 / 2} \\
S K & =\left[m_{3}^{\prime}-3 \cdot m_{2}^{\prime} \cdot m_{1}^{\prime}+2 \cdot\left(m_{1}^{\prime}\right)^{3}\right]^{1 / 3} .
\end{aligned}
$$

$S K$ denotes the third root of the third central moment of D. This monotonous transformation yields more manageable numbers, as the numerical values of the third central moment may be very large. 
Table 2

Estimates of Mean, Standard Deviation, and Skewness of $D_{L}$ and $D_{R}$

\begin{tabular}{|c|c|c|c|c|}
\hline \multirow[b]{2}{*}{ Subject } & \multirow[b]{2}{*}{ Variable } & \multicolumn{3}{|c|}{ Central Moments (msec) } \\
\hline & & $M$ & $S D$ & $S K$ \\
\hline \multicolumn{5}{|c|}{ Part 1: Benussi (1913) } \\
\hline & $\begin{array}{r}\mathbf{D}_{\mathrm{R}} \\
\mathbf{D}_{\mathbf{L}} \\
\text { Difference } \\
S E \text { of Difference }\end{array}$ & $\begin{array}{r}45 \\
-34 \\
79 \\
3\end{array}$ & $\begin{array}{r}55 \\
65 \\
-9 \\
3\end{array}$ & $\begin{array}{r}-59 \\
68 \\
-127 \\
6\end{array}$ \\
\hline \multicolumn{5}{|c|}{ Part 2: Allan (1975a)-Successiveness/Order Task } \\
\hline T.M. & $\begin{array}{r}\mathbf{D}_{\mathrm{R}} \\
\mathbf{D}_{\mathbf{L}} \\
\text { Difference } \\
S E \text { of Difference }\end{array}$ & $\begin{array}{r}53 \\
-36 \\
90 \\
3\end{array}$ & $\begin{array}{r}51 \\
53 \\
-2 \\
3\end{array}$ & $\begin{array}{r}-60 \\
55 \\
-115 \\
5\end{array}$ \\
\hline A.J. & $\begin{array}{r}D_{\mathrm{R}} \\
\mathrm{D}_{\mathrm{L}} \\
\text { Difference } \\
S E \text { of Difference }\end{array}$ & $\begin{array}{r}40 \\
-24 \\
64 \\
3\end{array}$ & $\begin{array}{r}67 \\
68 \\
-1 \\
2\end{array}$ & $\begin{array}{r}-68 \\
64 \\
-132 \\
4\end{array}$ \\
\hline B.P. & $\begin{array}{r}\mathbf{D}_{\mathbf{R}} \\
\mathbf{D}_{\mathbf{L}} \\
\text { Difference } \\
S E \text { of Difference }\end{array}$ & $\begin{array}{r}44 \\
-28 \\
71 \\
3\end{array}$ & $\begin{array}{r}74 \\
71 \\
3 \\
3\end{array}$ & $\begin{array}{r}-76 \\
62 \\
-138 \\
5\end{array}$ \\
\hline
\end{tabular}

Part 3: Allan (1975b)-Confidence-Rating Task

\begin{tabular}{|c|c|c|c|c|}
\hline V.R. & $\begin{array}{r}\mathbf{D}_{\mathrm{R}} \\
\mathbf{D}_{\mathbf{L}} \\
\text { Difference } \\
S E \text { of Difference }\end{array}$ & $\begin{array}{r}42 \\
-46 \\
88 \\
3\end{array}$ & $\begin{array}{r}57 \\
50 \\
7 \\
3\end{array}$ & $\begin{array}{r}-58 \\
49 \\
-108 \\
4\end{array}$ \\
\hline L.M. & $\begin{array}{r}\mathbf{D}_{\mathbf{R}} \\
\mathbf{D}_{\mathbf{L}} \\
\text { Difference } \\
S E \text { of Difference }\end{array}$ & $\begin{array}{r}48 \\
-40 \\
88 \\
3\end{array}$ & $\begin{array}{r}66 \\
50 \\
16 \\
3\end{array}$ & $\begin{array}{r}-65 \\
52 \\
-117 \\
4\end{array}$ \\
\hline V.V. & $\begin{array}{r}\mathbf{D}_{\mathrm{R}} \\
\mathbf{D}_{\mathbf{L}} \\
\text { Difference } \\
S E \text { of Difference }\end{array}$ & $\begin{array}{r}23 \\
-23 \\
46 \\
2\end{array}$ & $\begin{array}{r}83 \\
74 \\
8 \\
2\end{array}$ & $\begin{array}{r}-64 \\
65 \\
-129 \\
4\end{array}$ \\
\hline B.M. & $\begin{array}{r}\mathbf{D}_{\mathbf{R}} \\
\mathbf{D}_{\mathbf{L}} \\
\text { Difference } \\
S E \text { of Difference }\end{array}$ & $\begin{array}{r}71 \\
-57 \\
128 \\
2\end{array}$ & $\begin{array}{r}74 \\
60 \\
15 \\
3\end{array}$ & $\begin{array}{r}-91 \\
69 \\
-160 \\
4\end{array}$ \\
\hline N.C. & $\begin{array}{r}\mathrm{D}_{\mathrm{R}} \\
\mathrm{D}_{\mathrm{L}} \\
\text { Difference } \\
S E \text { of Difference }\end{array}$ & $\begin{array}{r}45 \\
-24 \\
69 \\
2\end{array}$ & $\begin{array}{r}31 \\
26 \\
5 \\
2\end{array}$ & $\begin{array}{r}-27 \\
18 \\
-45 \\
16\end{array}$ \\
\hline A.T. & $\begin{array}{r}\mathbf{D}_{\mathrm{R}} \\
\mathbf{D}_{\mathbf{L}} \\
\text { Difference } \\
S E \text { of Difference }\end{array}$ & $\begin{array}{r}58 \\
-56 \\
114 \\
3\end{array}$ & $\begin{array}{r}78 \\
74 \\
4 \\
3\end{array}$ & $\begin{array}{r}-80 \\
84 \\
-163 \\
4\end{array}$ \\
\hline
\end{tabular}

Part 4: High Intensity (Present Study)

$\begin{array}{lrrrr}\text { U.D. } & \mathbf{D}_{\mathrm{R}} & 2 & 56 & -30 \\ & \mathbf{D}_{\mathrm{L}} & -20 & 53 & 46 \\ & \text { Difference } & 21 & 2 & -76 \\ \text { M.P. } & S E \text { of Difference } & 2 & 1 & 14 \\ & \mathbf{D}_{\mathrm{R}} & 41 & 56 & -58 \\ & \mathbf{D}_{\mathrm{L}} & -14 & 66 & 62 \\ \text { G.U. } & \text { Difference } & 54 & -10 & -120 \\ & S E \text { of Difference } & 3 & 2 & 4 \\ & \mathbf{D}_{\mathrm{R}} & 47 & 36 & -44 \\ & \mathbf{D}_{\mathbf{L}} & -28 & 46 & 56 \\ & S E \text { of Difference } & 75 & -10 & -100 \\ & & 2 & 3 & 5\end{array}$

$-58$

49
-108

4

65

117

4

64

65

129
4

$-91$

69

4

$-27$

18
-45

$-80$

84

4

$-30$

-30
-76

-76
14

$-58$

62

4

$-44$

56

5
Table 2 (Continued)

\begin{tabular}{|c|c|c|c|c|}
\hline \multirow[b]{2}{*}{ Subject } & \multirow[b]{2}{*}{ Variable } & \multicolumn{3}{|c|}{ Central Moments (msec) } \\
\hline & & $M$ & $S D$ & $S K$ \\
\hline \multicolumn{5}{|c|}{ Part 5: Low Intensity (Present Study) } \\
\hline U.D. & $\begin{array}{r}\mathbf{D}_{\mathrm{R}} \\
\mathbf{D}_{\mathrm{L}} \\
S E \text { of Difference }\end{array}$ & $\begin{array}{r}65 \\
-3 \\
69 \\
3\end{array}$ & $\begin{array}{r}64 \\
84 \\
-20 \\
3\end{array}$ & $\begin{array}{r}-72 \\
63 \\
-135 \\
5\end{array}$ \\
\hline M.P. & $\begin{array}{r}D_{R} \\
D_{\mathbf{L}} \\
\text { Difference } \\
S E \text { of Difference }\end{array}$ & $\begin{array}{r}31 \\
-31 \\
61 \\
3\end{array}$ & $\begin{array}{r}73 \\
67 \\
7 \\
2\end{array}$ & $\begin{array}{r}-65 \\
69 \\
-134 \\
4\end{array}$ \\
\hline G.U. & $\begin{array}{r}\mathbf{D}_{\mathbf{R}} \\
\mathbf{D}_{\mathrm{L}} \\
\text { Difference } \\
S E \text { of Difference }\end{array}$ & $\begin{array}{r}49 \\
-36 \\
85 \\
3\end{array}$ & $\begin{array}{r}41 \\
42 \\
-1 \\
3\end{array}$ & $\begin{array}{r}-49 \\
53 \\
-102 \\
5\end{array}$ \\
\hline
\end{tabular}

Note-All values are rounded to the nearest millisecond. $S K=$ skewness.

The above procedure was used to estimate $M_{\mathrm{L}}, S D_{\mathrm{L}}$, and $S K_{L}$ of $D_{L}$ from the empirical function of $Y_{L}$; and the estimates $M_{R}, S D_{R}$, and $S K_{R}$ of $D_{R}$ from the empirical function of $\boldsymbol{Y}_{\mathbf{R}}$. Table 2 summarizes these estimates for the data sets of Benussi (1913), Allan (1975a, 1975b), and the present experiment.

Table 2 provides also the differences $M_{R}-M_{L}$, $S D_{\mathrm{R}}-S D_{\mathrm{L}}$, and $S K_{\mathrm{R}}-S K_{\mathrm{L}}$ for each data set. As these differences are especially important in order to evaluate the above predictions, the corresponding standard errors (SEs) were estimated by the bootstrapping procedure (see Diaconis \& Efron, 1983; Efron \& Gong, 1983). In essence, the bootstrapping procedure takes the observed response proportions of $x y, s i$, and $y x$ as estimates for the probabilities $\operatorname{Pr}\left\{x y \mid d_{i}\right\}, \operatorname{Pr}\left\{s i \mid d_{i}\right\}$, and $\operatorname{Pr}\left\{y x \mid d_{i}\right\}$, $i=1, \ldots, N$. (1) These estimates are used to simulate the experiment again, yielding a bootstrap sample. (2) The data of the bootstrap sample are used to compute the socalled bootstrap replications, that is, the value of the statistics, in this case the differences $M_{R}-M_{L}, S D_{R}-S D_{L}$, and $S K_{R}-S K_{L}$. (3) Steps 1 and 2 are repeated for some large number $(B)$ of times, obtaining $B$ independent bootstrap replications. (4) Finally the $S E$-for example, of the difference $\boldsymbol{M}_{\mathrm{R}}-\boldsymbol{M}_{\mathrm{L}}$-is given by computing the standard deviation of the corresponding bootstrap replications. Steps 1-4 with $B=100$ were carried out for all data sets in Table $2 .^{5}$

\section{Are the Predictions Consistent with the Data?}

Table 2 provides the necessary information for a quick answer.

Skewness property. A clear pattern of results is obtained for the skewness relationship of $Y_{L}$ and $Y_{R}$. For all data sets, the relationship $S K_{L}>S K_{R}$ holds. This finding is inconsistent with the prediction of the perceptualmoment hypothesis. Furthermore, this finding automatically violates the parallelism property: $Y_{L}$ and $Y_{R}$ are nonparallel functions. If one proceeds from triggered-moment 
models, one has to assume that the central moment of the moment duration is negative to account for this finding (see Equation 3). However, this would be a rather exceptional assumption, as latency distributions usually have a positive third central moment.

Equal dispersion property. In 11 of 16 cases the standard deviations of $D_{\mathbf{L}}$ and $\mathbf{D}_{\mathrm{R}}$ differ more than expected by chance alone [criterion: $\left|S D_{\mathrm{L}}-S D_{\mathrm{R}}\right|>2 \cdot S E$ ]. This finding is inconsistent with the predictions of the perceptual-moment hypothesis, triggered-moment models, and attention-switching models if attention is initially directed to both channels with equal probabilities.

Invariance property of $E\left(D_{R}\right)-E\left(D_{L}\right)$. For all 3 subjects in the present experiment, the difference $E\left(D_{R}\right)-E\left(D_{L}\right)$ increased with decreasing intensity of the flash pair. The increases were $47 \mathrm{msec}(S E=3.4), 7 \mathrm{msec}$ $(S E=3.5)$, and $10 \mathrm{msec}(S E=3.3)$ for Subjects U.D., M.P., and G.U., respectively. This finding contradicts the notion that the central-decision process is independent of stimulus properties-an implicit assumption of all specific threshold models. The thresholds $\mathbf{C}_{\mathrm{xy}}$ and $\mathbf{C}_{\mathbf{y x}}$ must somehow depend on stimulus intensity.

Predicted and observed moments of $\mathbf{D}_{\mathbf{M}}$. Table 3 shows observed and predicted central moments of $D_{M}$ for the data presented by Allan (1975a, 1975b). The modified S-K method was again applied to compute the central moments for each subject. The central moments of $D_{R}$ and $D_{L}$ and the estimate of $\beta$ in Table 3 were used to compute predicted central moments. Standard errors of the difference between observed and predicted values were again estimated by the bootstrapping procedure. Observed and predicted values agreed surprisingly well. No significant difference between the two values was found for the successiveness/order task (Allan, 1975a). Only in the confidence-rating task (Allan, 1975b) were the SDs for Subjects V.R., L.M., and N.C. slightly overpredicted. On the whole, the result is consistent with the general threshold model and the assumed response mapping.

Averaging artifacts? I have already mentioned the problem of averaging psychometric functions. The results in Table 2 of my own experiment are based on averaging the data of 10 daily sessions. Some intersession variability is naturally unavoidable, for example, due to changes in the subject's pattern of responding. Hence, the doubtful point is whether the average psychometric function shows features that are nonexistent in the psychometric functions of the daily sessions. To explore this possibility, I performed the above data analysis for each daily session. This analysis revealed two things: (1) The estimates $M, S D$, and $S K$ from the daily sessions were quite stable over the 10 sessions. (2) The averaged estimates from the 10 sessions were nearly the same as the ones shown in Table 2. (The $S D$ s and the absolute values of the $S K$ s were slightly smaller for the single-session analysis.) Furthermore, it can be shown that the nonmonotone results cannot be explained by averaging artifacts: Let $\operatorname{Pr}_{\mathrm{i}}\{\mathbf{D} \leq d\}$ be the psychometric function of session $i(i=1, \ldots, 10)$. If we assume that threshold models hold,
Table 3

Observed and Predicted Mean, Standard Deviation, and Skewness of $\mathbf{D}_{M}$

Central Moments (msec)

\begin{tabular}{|c|c|c|c|c|}
\hline Subject & $M$ & $S D$ & $S K$ & $\beta_{\text {est. }}$ \\
\hline
\end{tabular}

Part 1: Allan (1975a)-Successiveness/Order Task

$\begin{array}{lllll}\text { T.M. } & \text { Observed } & 1 & 67 & 29\end{array}$

$\begin{array}{lrrr}\text { Predicted } & 3 & 68 & 12\end{array}$

Difference $\quad-2 \quad-1 \quad 17$

$S E$ of Difference $\quad 1 \quad 16$

$\begin{array}{lllll}\text { A.J. } & \text { Observed } & 3 & 74 & 28\end{array}$

$\begin{array}{llll}\text { Predicted } & 5 & 75 & 21\end{array}$

$\begin{array}{llll}\text { Difference } & -2 & -1 & 7\end{array}$

$S E$ of Difference $\quad 1 \quad 1 \quad 16$

B.P. Observed $\quad-1 \quad 81 \quad 31$

$\begin{array}{llll}\text { Predicted } & -2 & 80 & 34\end{array}$

$\begin{array}{lllr}\text { Difference } & 1 & 1 & -3 \\ & 1 & 1 & 16\end{array}$

0.59

$S E$ of Difference

Part 2: Allan (1975b)-Confidence-Rating Task

$\begin{array}{llllll}\text { V.R. } & \text { Observed } & -10 & 55 & 31 & 0.58\end{array}$

$\begin{array}{lrrr}\text { Predicted } & -9 & 68 & 39\end{array}$

Difference $\quad-1 \quad-13 \quad-8$

$S E$ of Difference $\quad 1 \quad 1 \quad 10$

L.M. Observed $\quad-6 \quad 62 \quad 46$

Predicted $\quad-4 \quad 71 \quad 50$

Difference $\quad-2 \quad-11 \quad-4$

$S E$ of Difference $\quad 1, \quad 2 \quad 3$

$\begin{array}{llllll}\text { V.V. } & \text { Observed } & -1 & 82 & 40 & 0.55\end{array}$

$\begin{array}{llll}\text { Predicted } & -2 & 81 & 44\end{array}$

$\begin{array}{llll}\text { Difference } & 1 & 1 & -4\end{array}$

$S E$ of Difference $\quad 1 \quad 1 \quad 4$

$\begin{array}{lllll}\text { B.M. } & \text { Observed } & -1 & 90 & 47\end{array}$

$\begin{array}{llll}\text { Predicted } & -2 & 92 & 47\end{array}$

Difference $\quad 1 \quad-2 \quad 0$

SE of Difference $\quad 1 \quad 2$

N.C. Observed $\quad 9 \quad 33 \quad 26$

$\begin{array}{llll}\text { Predicted } & 11 & 45 & 19\end{array}$

$\begin{array}{llll}\text { Difference } & -2 & -8 & 7\end{array}$

$S E$ of Difference $\quad 1 \quad 2 \quad 13$

$\begin{array}{lllll}\text { A.T. } & \text { Observed } & -11 & 91 & 62\end{array}$

Predicted $\quad-11 \quad 94 \quad 65$

$\begin{array}{rrrr}\text { Difference } & 0 & -3 & -3 \\ S E \text { of Difference } & 1 & 2 & 2\end{array}$

0.60

0.56

0.49

0.60

Note-All values are rounded to the nearest millisecond. $S K=$ skewness; $\beta_{\text {est. }}=$ estimated $\beta$.

then $\operatorname{Pr}_{\mathrm{i}}\{\mathrm{D} \leq d\}$ must be monotonically increasing. The average function is then given by $\operatorname{Pr}\{\mathbf{D} \leq d\}=$ $\left[\Sigma \operatorname{Pr}_{\mathbf{i}}\{\mathrm{D} \leq d\}\right] / 10$. Differentiating with respect to $d$ shows that $\operatorname{Pr}\{\mathrm{D} \leq d\}$ must be monotone if all $\operatorname{Pr}_{\mathbf{i}}\{\mathbf{D} \leq d\} \mathrm{s}(i=1, \ldots, 10)$ are monotone. In sum, averaging the data of the daily sessions did not produce artifacts.

\section{CONCLUDING COMMENTS}

The results demonstrate that the ternary TOJ approach yields more powerful data than do binary TOJs. Within the framework of threshold models it was possible to isolate aspects of the central order-decision process without the need to make ancillary assumptions about the percep- 
tual latencies. Such an isolation would be impossible for the traditional approach.

The present approach provides new constraints for future models and for modifications of present threshold models. The constraints may be summarized as follows: (1) The dominance property has to be satisfied. (2) The skewness relationship $S K_{\mathrm{L}}>S K_{\mathrm{R}}$ has to be predicted. (3) A model must be capable of producing different dispersion relationships between $Y_{L}$ and $Y_{R}$. (4) It would be desirable for a model to be able to account for the violation of the invariance property of $E\left(D_{R}\right)-E\left(D_{L}\right)$ as observed in the present experiment. (5) Although the violation of the monotonicity property is difficult to assess statistically, it would be instructive to provide a model that is capable of predicting nonmonotonous as well as monotonous shapes of $Y_{L}$ and $Y_{R}$. (Suggestions in this direction are provided by Sternberg et al., 1975, pp. 13-16, and Ulrich, 1983.)

The violation of the invariance property is a crucial finding for threshold models. It is difficult, for example, to imagine a modification for the perceptual-moment hypothesis that could reconcile this hypothesis with this finding, in addition to which, this hypothesis cannot account for constraints 2, 3, and 5 .

However, a modification of the attention-switching model that reconciles the model with this finding is quite easy to imagine. This modification assumes that the dwell times in channels $y$ and $x$ depend on stimulus intensity. As an example, assume a periodic switching process to channels $x$ and $y$. Once attention is switched to a channel, evidence in favor of stimulus presence is accumulated over time, for example, by a random walk process (Laming, 1968; Link \& Heath, 1975). Attention is switched away from a channel as soon as the status of stimulus presence versus stimulus absence is clarified. In terms of a random walk model, attention is switched away from a channel if the random walk process crosses the boundary indicating stimulus presence or the boundary indicating stimulus absence. It is clear that information regarding stimulus presence is accumulated faster for an intense stimulus. In terms of a random walk model, the drift of the random walk process toward the signal presence boundary is greater for an intense stimulus. Consequently, dwell time would depend on stimulus intensity-the lower the intensity the longer the dwell time. It follows that thresholds $\mathbf{C}_{\mathbf{x y}}$ and $\mathbf{C}_{\mathbf{y x}}$ increase with decreasing intensity, accounting for the violation of the invariance property.

Can attention-switching models account for constraints 1-3? To provide an answer to this question I assumed $\mathbf{Q}$ to be exponentially distributed and computed via Equations $4 a$ and $4 b$ the appropriate moments for $D_{L}$ and $D_{R}$. To render the mathematics of the model tractable, I assumed that the mean dwell times in a channel for both signal presence and signal absence are equal. In more realistic versions of the attention-switching model one would surely assume different means. This computation revealed that for particular choices of model parameters it is possible to generate predictions in accordance with constraints 1-3. This idea of a modified attentionswitching model seems very promising.

Allan (1975a) extended Kristofferson's (1967a) attentionswitching model, with constant $\mathbf{Q}$, to her successiveness/ order data. She fitted the model and was able to predict the shapes of the obtained psychometric functions. Although Allan did not modify the basic assumptions of the model, she assumed a more complex response mapping than the one described above. This more complex mapping requires the estimation of two additional guessing parameters (cf. Figure 4 in Allan, 1975a). Consequently, Allan (1975a) reconciles the attention-switching model with the crucial finding of nonparallel psychometric functions by the assumption of a more complex response mapping. However, our distribution-free approach showed that a more complex response mapping is not needed to account for Allan's (1975a) successiveness/ order data (cf. Table 3). Therefore, our analysis suggests that the original version of the attention-switching model fails not because the above less complex response mapping is wrong, but because one or more of the model's basic assumptions is wrong (e.g., that $Q$ is a random variable instead of a constant). Model fits improve with the number of free parameters. This may be the reason Allan (1975a) was able to fit the model, although the original model version is probably wrong.

Proponents of the attention-switching model might argue that the present experiment is not a critical test of the original version of the model, because unimodal stimuli can be monitored simultaneously, without the need to shift attention from one point to another in the visual field. However, recent research contradicts this notion (see, e.g., Posner, Nissen, \& Odgen, 1978; Reeves \& Sperling, 1986; Sperling, 1984). Further research with bimodal stimuli is needed to clarify this point.

\section{REFERENCES}

Allan, L. G. (1975a). The relationship between judgments of successiveness and judgments of order. Perception \& Psychophysics, 18, 29-36.

Allan, L. G. (1975b). Temporal order psychometric functions based on confidence-rating data. Perception \& Psychophysics, 18, 369-372.

Allan, L. G., \& Kristofferson, A. B. (1974). Successiveness discrimination: Two models. Perception \& Psychophysics, 15, 37-46.

Allport, D. A. (1968). Phenomenal simultaneity and the perceptual moment. British Jourmal of Psychology, 59, 395-406.

Ayer, M., Brunk, H. D., Ewing, G. M., Reid, W. T., \& SilverMAN, E. (1955). An empirical distribution function for sampling with incomplete information. Annals of Mathematical Statistics, 26, 641-647.

BAER, K. E., vON (1862). Welche Auffassung der lebenden Natur ist die richtige? Wie ist diese Auffassung auf die Entomologie anzuwenden? [Which conception of living nature is correct? How can one apply this conception to entomology?]. Opening speech given at the foundation of the Russian Association of Entomology in May 1860. Berlin: August Hirschwald.

Baron, J. (1971). The threshold for successiveness. Perception \& Psychophysics, 10, 201-207.

BENUssi, V. (1913). Psychologie der Zeitauffassung [Psychology of the conception of time]. Heidelberg: Carl Winter's Universitätshandlung. 
BoRING, E. G. (1950). A history of experimental psychology (2nd ed.). New York: Appleton-Century-Crofts. .

BREITMEYER, B. G. (1984). Visual masking: An integrative approach. New York: Oxford University Press.

BUNGE, M. (1983). Epistemologie: Aktuelle Fragen der Wissenschaftstheorie [Topical questions of epistemology]. Mannheim, West Germany: Bibliographisches Institut AG.

Cox, D. R., Isham, V. (1980). Point processes. London: Chapman \& Hall.

Coombs, C. H. (1984). Theory and experiment in psychology. In D. Albert, K. Pawlik, K.-H. Stapf, \& W. Stroebe (Eds.), Fortschritte der Experimentalpsychologie, Hamburger Mittagsvorlesungen 1983 [Advances in experimental psychology, Hamburg midday lectures 1983] (pp. 20-30). Berlin: Springer-Verlag.

DiACONIS, P., \& EFRON, B. (1983). Computer-intensive methods in statistics. Scientific American, 248, 116-130.

EFron, B., GONG, G. (1983). A leisurely look at the bootstrap, the jacklnife, and cross-validation. The American Statistician, 37, 36-48. EFron, R. (1967). The duration of the present. Annals of the New York Academy of Sciences, 138, 713-729.

EFron, R., \&Ee, D. N. (1971). The visual persistence of a moving stroboscopically illuminated object. American Journal of Psychology, 84, 365-375.

Epstern, B., \& Churchman, C. W. (1944). On the statistics of sensitivity data. Annals of Mathematical Statistics, 15, 90-96.

Eschweiler, G., PopP, M., Rauschecker, J. P., \& Schrader, W. (1984). Timing of flash responses in visual cortex of normal and strabismic cats. Society for Neuroscience Abstracts, 10, 469.

EsTES, W. K. (1956). The problem of inference from curves based on group data. Psychological Bulletin, 53, 134-140.

FALMaGne, J.-C. (1985). Elements of psychophysical theory. New York: Oxford University Press.

Fraisse, P. (1978). Time and rhythm perception. In E. C. Carterette \& M. P. Friedman (Eds.) Handbook of perception: Vol. 8: Perceptual coding (pp. 203-254). New York: Academic Press.

Fraisse, P. (1984). Perception and estimation of time. Annual Review of Psychology, 35, 1-36.

FröHulch, F. W. (1929). Die Empfindungszeit: Ein Beitrag zur Lehre von der Zeit-, Raum- und Bewegungsempfindung [Perceptual latency: A contribution to the theory of time, space and motion perception]. Jena, East Germany: Verlag von Gustav Fischer.

Gibbon, J., \& Rutschman, R. (1969). Temporal order judgement and reaction time. Science, 165, 413-415.

Grice, G. R. (1968). Stimulus intensity and response evocation. Psychological Review, 75, 359-373.

HARTER, M. R. (1967). Excitability cycles and cortical scanning: A review of two hypotheses of central intermittency in perception. Psychological Bulletin, 68, 47-58.

HARTER, M. R., \& WhITE, C. R. (1967). Perceived number and evoked potentials. Science, 156, 406-408.

HEATH, R. A. (1984). Response time and temporal order judgement in vision. Australian Journal of Psychology, 36, 21-34.

KrISTOFFERSON, A. B. (1967a). Attention and psychological time. Acta Psychologica, 27, 93-100.

KrISTOFFERSON, A. B. (1967b). Successiveness discrimination as a twostate, quantal process. Science, 158, 1337-1339.

LAMING, D. R. (1968). Information theory of choice-reaction times. New York: Academic Press.

LATOUR, P. L. (1967). Evidence of internal clocks in the human operator. Acta Psychologica, 27, 341-348.

LeviCK, W. R. (1973). Variation in the response latency of cat retinal ganglion cells. Vision Research, 13, 837-853.

LiNK, S. W., Heath, R. A. (1975). A sequential theory of psychological discrimination. Psychometrika, 40, 77-105.

Mejuers, L. M. M., \& EuKMAN, E. G. J. (1974). The motor system in simple reaction experiments. Acta Psychologica, 38, 367-377.

Meyer, D. E., Yantis, S., Osman, A. M., Smith, J. E. K. (1985). Temporal properties of human information processing: Tests of discrete versus continuous models. Cognitive Psychology, 17, 445-518.
Möcks, J., Gasser, T., Pham, D. T. (1984). Variability of single visual evoked potentials evaluated by two new statistical tests. Electroencephalography \& Clinical Neurophysiology, 57, 571-580.

Möcks, J., Gasser, T., Pham, D. T., \& Köhler, W. (1987). Trialto-trial variability of single event-related potentials: New concepts and results. Intermational Journal of Neuroscience, 33, 25-32.

Neumann, O. (1984). Moment III, Psychologie. In J. Ritter (Ed.), Worterbuch der Philosophie (Vol. 6, pp. 108-114). Stuttgart, West Germany: Schwabe.

PöPPEL, E. (1970). Excitability cycles in central intermittency. Psychologische Forschung, 34, 1-9.

PöPPEL, E. (1978). Time perception. In R. Held, H. W. Leibowitz, \& H.-L. Teuber (Eds.), Handbook of sensory physiology (Vol. 8, pp. 713-729). Berlin: Springer-Verlag.

Posner, M. I., Nissen, M. J., \& ODGen, W. C. (1978). Attended and unattended processing modes: The role of set for spatial location. In H. I. Pick, Jr., \& E. Saltzman (Eds.), Models of perceiving and processing information. Hillsdale, NJ: Erlbaum.

Rauschecker, J. P., Popp, M., \& Eschweiler, G. (1986). Latency and precision of single-cell responses in visual cortex and their relevance for spatio-temporal interpolation models. Behavioral Brain Research, 20, 134.

REEVES, A., \& SPERING, G. (1986). Attentional gating in visual shortterm memory. Psychological Review, 93, 180-206.

SPEARMan, C. (1908). The method of 'right and wrong cases' ('constant stimuli') without Gauss's formulae. British Journal of Psychology, 2, 227-242.

SPERLING, G. (1984). A unified theory of attention and signal detection. In R. Parasuraman \& D. R. Davies (Eds.), Varieties of Attention (pp. 103-181). New York: Academic Press.

STERNBERG, S. (1969). The discovery of processing stages: Extensions of Donder's method. Acta Psychologica, 30, 276-315.

STERNBERG, S., KNOLL, R. L. (1973). The perception of temporal onder: Fundamental issues and a general model. In S. Kornblum (Ed.), Attention and performance $I V$ (pp. 629-685). New York: Academic Press.

Sternberg, S., Knoll, R. L., Mallows, C. L. (1975). Conditions for parallel psychometric functions based on rating-scale data: Applications to temporal-order judgements (Technical memorandum, Bell Laboratories, Murray Hill, NJ).

SternberG, S., KnOLl, R. L., \& ZuKoFsky, P. (1982). Timing by skilled musicians. In D. Deutsch (Ed.), The psychology of music (pp. 181-239). New York: Academic Press.

STroud, J. M., (1955). The fine structure of psychological time. In H. Quastler (Ed.), Information theory in psychology (pp. 174-205). Glencoe, IL: Free Press.

ULRICH, R. (1983). Zur Psychophysik der Zeitwahrnehmung: Theoretische und experimentelle Analysen des Reihenfolgeurteils [Psychophysics of time perception: Theoretical and experimental analyses of temporal-order judgments]. Unpublished doctoral thesis, Universität Tübingen, Tübingen, West Germany.

ULRICH, R., STAPF, K. H. (1984). A double-response paradigm to study stimulus intensity effects upon the motor system in simple reaction time experiments. Perception \& Psychophysics, 36, 545-558.

UTTAL, W. R. (1981). A taxonomy of visual processes. Hillsdale, NJ: Erlbaum.

Venables, P. H. (1960). Periodicity in reaction time. British Journal of Psychology, 51, 37-43.

VORBERG, D. (1985). Unerwartete Folgen von zufälliger Variabilität: Wettlauf-Modelle für den Stroop-Versuch [Unexpected consequences of random variability: Race models for the Stroop paradigm]. Zeitschrift fur experimentelle und angewandte Psychologie, 32, 494-521.

ZACKS, J. L. (1973). Estimation of the variability of the latency of responses to brief flashes. Vision Research, 13, 829-835.

\section{NOTES}

1. It should be noted that Allan (1975a) did not use the three response categories $x y, y x$, and si directly. However, it is possible to analyze 
her data accordingly, as will be evident in the section Threshold Models and Confidence Rating Data.

2. The phrase "arrival of sensory messages" has a broader meaning than it suggests: On the one hand, this phrase can mean that the sensory messages $m_{\mathrm{x}}$ and $m_{\mathrm{y}}$ are internal punctate stimuli whose arrivals are registered in an all-or-nothing fashion. On the other hand, one might assume that evidence for a stimulus, say $S_{\mathbf{x}}$, starts to grow with stimulus onset and continues until enough activation is produced to cross a corresponding threshold (Grice, 1968). In this second case "arrival of $m_{\mathrm{x}}$ '" means the time point when the activation produced by $S_{\mathrm{x}}$ crosses a corresponding threshold. The considerations and conclusions about threshold models will apply to both interpretations.

3. Even if $C$ is correlated with latencies $L_{x}$ and $L_{y}$, the equal-spread prediction should hold approximately. Consider, for example, the variance of $\mathbf{D}_{\mathbf{R}}$ :

$$
\begin{aligned}
\operatorname{var}\left(\mathbf{D}_{\mathbf{R}}\right)= & \operatorname{var}\left(\mathbf{L}_{\mathbf{x}}-\mathbf{L}_{\mathbf{y}}+\mathbf{C}\right) \\
= & \operatorname{var}\left(\mathbf{L}_{\mathbf{x}}\right)+\operatorname{var}\left(\mathbf{L}_{\mathbf{y}}\right)-2 \operatorname{cov}\left(\mathbf{L}_{\mathbf{x}}, \mathbf{L}_{\mathbf{y}}\right)+\operatorname{var}(\mathbf{C}) \\
& +2 \operatorname{cov}\left(\mathbf{L}_{\mathbf{x}}, \mathbf{C}\right)-2 \operatorname{cov}\left(\mathbf{L}_{\mathbf{y}}, \mathbf{C}\right) \\
= & \operatorname{var}(\mathbf{U})+\operatorname{var}(\mathbf{C})+2\left[\operatorname{cov}\left(\mathbf{L}_{\mathbf{x}}, \mathbf{C}\right)-\operatorname{cov}\left(\mathbf{L}_{\mathbf{y}}, \mathbf{C}\right)\right]
\end{aligned}
$$

In a similar fashion one obtains

$$
\operatorname{var}\left(\mathbf{D}_{\mathbf{L}}\right)=\operatorname{var}(\mathbf{U})+\operatorname{var}(\mathbf{C})+2\left[\operatorname{cov}\left(\mathbf{L}_{\mathbf{y}}, \mathbf{C}\right)-\operatorname{cov}\left(\mathbf{L}_{\mathbf{x}}, \mathbf{C}\right)\right]
$$

Therefore, if $\operatorname{cov}\left(L_{x}, C\right) \approx \operatorname{cov}\left(L_{y}, C\right)$, it follows that $\operatorname{var}\left(D_{L}\right) \approx \operatorname{var}\left(D_{R}\right)$. Consequently, if the empirical estimates of $\operatorname{var}\left(\mathbf{D}_{\mathrm{L}}\right)$ and $\operatorname{var}\left(\mathbf{D}_{\mathrm{R}}\right)$ differ extremely, one would be in doubt about triggered-moment models in general.

4. Values of $125 \mathrm{msec}$ and $-125 \mathrm{msec}$ were used for $d_{N+1}$ and $d_{0}$, respectively. The selection of these values is justified by the fact that all subjects showed perfect temporal-order discrimination at these extremes in a pilot study. When I changed these values to, for example, $150 \mathrm{msec}$ and $-150 \mathrm{msec}$, respectively, the same conclusions were obtained, although slightly different estimates of the moments resulted for these latter values.

5. A more complete justification of this method for estimating the parameters is desirable. Although I have no analytical results to offer at this time, I have conducted Monte Carlo simulations to evaluate the method of analysis. In each simulation experiment a particular threshold model was assumed, and the simulation was designed to find out whether the true model parameters could be recovered by the estimation procedure. I have found that this is indeed the case and that the variability of the estimated parameters (standard error of estimate) is well assessed by the bootstrapping procedure.

\section{APPENDIX A}

Proof of Equation la:

$$
\begin{aligned}
\boldsymbol{Y}_{\mathbf{R}}(d) & =\operatorname{Pr}\{x y \mid d\} \\
& =\operatorname{Pr}\left\{\mathbf{A}_{\mathbf{x}}+\mathbf{C}_{\mathbf{x y k}}<\mathbf{A}_{\mathbf{y}}\right\} \text { (see Assumption 1) } \\
& =\operatorname{Pr}\left\{\mathbf{L}_{\mathbf{x}}+t_{\mathbf{x}}+\mathbf{C}_{\mathbf{x y}}<\mathbf{L}_{\mathbf{y}}+t_{\mathbf{x}}+d\right\} \\
& =\operatorname{Pr}\left\{\mathbf{L}_{\mathbf{x}}-\mathbf{L}_{\mathbf{y}}+\mathbf{C}_{\mathbf{x y}}<d\right\} \\
& =\operatorname{Pr}\left\{\mathbf{D}_{\mathbf{R}}<d\right\} \\
& =\operatorname{Pr}\left\{\mathbf{D}_{\mathbf{R}} \leq d\right\} \text { (as } \mathbf{D}_{\mathbf{R}} \text { is continuous). }
\end{aligned}
$$

The proof is complete because the last expression is the CDF of the random variable $D_{R}$, defined as $D_{R} \equiv L_{x}-L_{y}+C_{x y}$. The proof for Equation $1 \mathrm{~b}$ is similar.

\section{APPENDIX B}

Proof of Dominance Property $Y_{\mathrm{L}}(d) \geq Y_{\mathrm{R}}(d)$ :

By definition,

$$
\begin{aligned}
Y_{\mathbf{L}}(d) & =\operatorname{Pr}\{\mathbf{U}-\mathbf{C} \leq d\} \\
& =\iint_{u-c \leq d} f(\mathbf{U}=u \cap \mathbf{C}=c) d u d c,
\end{aligned}
$$

where $f(\mathbf{U}=u \cap \mathbf{C}=c)$ is the bivariate distribution of $\mathbf{U}$ and C. The above double integral can be rewritten as

$$
Y_{\mathrm{L}}(d)=\int_{0}^{\infty} \int_{-\infty}^{d+c} f(\mathrm{U}=u \cap \mathbf{C}=c) d u d c,
$$

and partitioned into the following two double integrals:

$$
\begin{aligned}
Y_{\mathbf{L}}(d)= & \int_{0}^{\infty} \int_{-\infty}^{d+c} f(\mathbf{U}=u \cap \mathbf{C}=c) d u d c \\
& +\int_{0}^{\infty} \int_{d-c}^{d+c} f(\mathbf{U}=u \cap \mathbf{C}=c) d u d c \\
= & \int_{u+c \leq d} f(\mathbf{U}=u \cap \mathbf{C}=c) d u d c \\
& +\int_{d-c<u<d+c} f(\mathbf{U}=u \cap \mathbf{C}=c) d u d c \\
= & \operatorname{Pr}\{\mathbf{U}+\mathbf{C} \leq d\}+\operatorname{Pr}\{d-\mathbf{C}<\mathbf{U}<d+\mathbf{C}\} \\
= & Y_{\mathbf{R}}(d)+\operatorname{Pr}\{d-\mathbf{C}<\mathbf{U}<d+\mathbf{C}\} .
\end{aligned}
$$

$\operatorname{Pr}\{d-\mathbf{C}<\mathbf{U}<d+\mathbf{C}\} \geq 0$ must hold; hence, the supposed inequality $Y_{\mathrm{L}}(d) \geq Y_{\mathrm{R}}(d)$ follows. The proof is complete.

\section{APPENDIX C}

$$
\begin{aligned}
& \text { Proof of } \\
& \mathrm{E}\left\{\left[\mathrm{D}_{\mathrm{R}}-\mathrm{E}\left(\mathrm{D}_{\mathbf{R}}\right)\right]^{3}\right\}=2 \mathrm{E}\left\{[\mathrm{C}-\mathrm{E}(\mathrm{C})]^{3}\right\}+\mathrm{E}\left\{\left[\mathrm{D}_{\mathbf{L}}-\mathrm{E}\left(\mathrm{D}_{\mathbf{L}}\right)\right]^{3}\right\} \text { : }
\end{aligned}
$$

If $\mathbf{C}$ and $\mathbf{U}$ are independent variables, then it can be shown that the third central moment of the sums $D_{R}=U+C$ and $\mathbf{D}_{\mathbf{L}}=\mathbf{U}-\mathbf{C}$ is given by

$$
\mathbf{E}\left\{\left[\mathbf{D}_{\mathbf{R}}-\mathbf{E}\left(\mathbf{D}_{\mathbf{R}}\right)\right]^{3}\right\}=\mathrm{E}\left\{[\mathbf{U}-\mathbf{E}(\mathbf{U})]^{3}\right\}+\mathbf{E}\left\{[\mathbf{C}-\mathbf{E}(\mathbf{C})]^{3}\right\}
$$
and

$$
\mathrm{E}\left\{\left[\mathbf{D}_{\mathbf{L}}-\mathbf{E}\left(\mathbf{D}_{\mathbf{L}}\right)\right]^{3}\right\}=\mathrm{E}\left\{[\mathbf{U}-\mathrm{E}(\mathbf{U})]^{3}\right\}-\mathbf{E}\left\{[\mathbf{C}-\mathrm{E}(\mathbf{C})]^{3}\right\},
$$

respectively. Equation $2 \mathrm{C}$ has to be subtracted from Equation $1 \mathrm{C}$, which yields the desired result.

\section{APPENDIX D}

\section{Proof of}

$$
\begin{gathered}
\mathrm{E}\left(\mathbf{D}_{\mathbf{R}}\right)-\mathrm{E}\left(\mathbf{D}_{\mathbf{L}}\right)=2 \cdot \mathrm{E}(\mathbf{R})+\mathrm{E}(\mathbf{Q}): \\
\begin{aligned}
\mathrm{E}\left(\mathbf{D}_{\mathbf{R}}\right)-\mathrm{E}\left(\mathbf{D}_{\mathbf{L}}\right) & =\mathrm{E}\left(\mathbf{U}+\mathbf{C}_{\mathrm{xy}}\right)-\mathrm{E}\left(\mathbf{U}-\mathbf{C}_{\mathbf{y x}}\right) \\
& =\mathrm{E}\left(\mathbf{C}_{\mathrm{xy}}\right)+\mathrm{E}\left(\mathbf{C}_{\mathbf{y x}}\right) .
\end{aligned}
\end{gathered}
$$


From Equation (4a) follows

$$
\begin{aligned}
\mathrm{E}\left(\mathbf{C}_{\mathbf{x y}}\right) & =P_{\mathbf{x}} \cdot \mathrm{E}(\mathbf{R})+\left(1-p_{\mathbf{x}}\right) \cdot \mathrm{E}(\mathbf{R}+\mathbf{Q}) \\
& =\mathrm{E}(\mathbf{R})+\left(1-p_{\mathbf{x}}\right) \cdot \mathrm{E}(\mathbf{Q})
\end{aligned}
$$

Similarly, from Equation (4b) follows

$$
\begin{aligned}
\mathrm{E}\left(\mathbf{C}_{\mathbf{y x}}\right) & =\left(1-p_{\mathbf{x}}\right) \cdot \mathrm{E}(\mathbf{R})+p_{\mathbf{x}} \cdot \mathrm{E}(\mathbf{R}+\mathbf{Q}) \\
& =\mathrm{E}(\mathbf{R})+p_{\mathbf{x}} \cdot \mathrm{E}(\mathbf{Q})
\end{aligned}
$$

Inserting $2 \mathrm{D}$ and $3 \mathrm{D}$ into $\mathrm{ID}$ yields the desired result.

\section{APPENDIX E}

\section{Proof of}

$Y_{M}(d) \equiv \operatorname{Pr}\left\{D_{M} \leq d\right\}=\beta \cdot \operatorname{Pr}\left\{D_{L} \leq d\right\}+(1-\beta) \cdot \operatorname{Pr}\left\{D_{R} \leq d\right\}:$

$Y_{M}$ is defined as

$$
Y_{\mathrm{M}}(d) \equiv \operatorname{Pr}\left\{x y_{\mathrm{c}} \mid d\right\}+\operatorname{Pr}\left\{x y_{\mathrm{u}} \mid d\right\} .
$$

According to the assumed response mapping and the general threshold model, we have

$$
\begin{aligned}
\operatorname{Pr}\left\{x y_{\mathrm{c}} \mid d\right\} & =\operatorname{Pr}\left\{\mathbf{A}_{\mathbf{x}}+\mathbf{C}_{\mathrm{xy}}<\mathbf{A}_{\mathbf{y}}\right\} \\
& =\operatorname{Pr}\left\{\mathbf{D}_{\mathbf{R}} \leq d\right\}
\end{aligned}
$$

and

$$
\begin{aligned}
\operatorname{Pr}\{x y \mathbf{y} \mid d\} & =\beta \cdot \operatorname{Pr}\left\{\mathbf{A}_{\mathbf{x}}<\mathbf{A}_{\mathbf{y}} \leq \mathbf{A}_{\mathbf{x}}+\mathbf{C}_{\mathbf{x y}} \text { or } \mathbf{A}_{\mathbf{y}}<\mathbf{A}_{\mathbf{x}} \leq \mathbf{A}_{\mathbf{y}}+\mathbf{C}_{\mathbf{y x}}\right\} \\
& =\beta \cdot\left[1-\operatorname{Pr}\left\{\mathbf{A}_{\mathbf{y}}+\mathbf{C}_{\mathbf{y x}}<\mathbf{A}_{\mathbf{x}}\right\}-\operatorname{Pr}\left\{\mathbf{A}_{\mathbf{x}}+\mathbf{C}_{\mathbf{x y}}<\mathbf{A}_{\mathbf{y}}\right\}\right] \\
& =\beta \cdot\left[\operatorname{Pr}\left\{\mathbf{D}_{\mathbf{L}} \leq d\right\}-\operatorname{Pr}\left\{\mathbf{D}_{\mathbf{R}} \leq d\right\}\right] .
\end{aligned}
$$

Inserting (3E) and (2E) into (1E) yields the desired result. An analogous derivation is used for Allan's (1975a) successiveness/order condition. The proof is complete.

\section{GLOSSARY}

This glossary provides brief definitions of main symbols used in the text and in the appendices.

TOJ Temporal-Order Judgment.

$S_{\mathrm{x}}\left(S_{\mathrm{y}}\right) \quad$ Stimulus in channel $x(y)$.

$t_{\mathrm{x}}\left(t_{\mathrm{y}}\right)$ Time at which $S_{\mathrm{x}}\left(S_{\mathrm{y}}\right)$ is presented.

$d$ Time difference $t_{\mathrm{y}}-t_{\mathrm{x}}$.

si Subjective report that $S_{\mathrm{x}}$ and $S_{\mathrm{y}}$ appear simultaneously. $x y$ Subjective report that $S_{\mathrm{x}}$ appears before $S_{\mathrm{y}}$.

$y x$ Subjective report that $S_{\mathrm{y}}$ appears before $S_{\mathrm{x}}$.

$m_{\mathrm{x}}\left(m_{\mathrm{y}}\right)$ Sensory message elicited by $S_{\mathrm{x}}\left(S_{\mathrm{y}}\right)$.

$Y_{\mathrm{L}}$ and $Y_{\mathrm{R}}$ Psychometric functions defined as $Y_{\mathrm{L}}(d) \equiv$ $1-\operatorname{Pr}\{y x \mid d\}$ and $Y_{\mathbf{R}}(d) \equiv \operatorname{Pr}\{x y \mid d\}$.

$\mathbf{L}_{\mathbf{x}}\left(\mathbf{L}_{\mathbf{y}}\right)$ Arrival latency of $m_{\mathrm{x}}\left(m_{\mathrm{y}}\right)$ at the locus of the central order-decision mechanism.

$\mathbf{A}_{\mathbf{x}}$ (A $\left.\mathbf{A}_{\mathbf{y}}\right)$ Arrival times of $m_{\mathbf{x}}\left(m_{\mathbf{y}}\right)$ at the locus of the central order-decision mechanism.

$\mathbf{C}_{\mathbf{x y}}$ Threshold applied to difference $\mathbf{A}_{\mathbf{y}}-\mathbf{A}_{\mathbf{x}}$ if $m_{\mathbf{x}}$ arrives at the central-order mechanism before $m_{\mathrm{y}}$.

$\mathbf{C}_{\mathbf{y x}}$ Threshold applied to difference $\mathbf{A}_{\mathbf{x}}-\mathbf{A}_{\mathbf{y}}$ if $m_{\mathbf{y}}$ arrives at the central-order mechanism before $m_{\mathrm{x}}$.

$\mathbf{U}$ Arrival latency difference $\mathbf{L}_{\mathbf{x}}-\mathbf{L}_{\mathbf{y}}$.

$\mathbf{D}_{\mathbf{R}}$ Random variable defined as $\mathbf{D}_{\mathbf{R}} \equiv \mathbf{U}+\mathbf{C}_{\mathbf{x y}}$.

$\mathbf{D}_{\mathrm{L}}$ Random variable defined as $\mathbf{D}_{\mathrm{L}} \equiv \mathbf{U}-\mathbf{C}_{\mathbf{y x}}$.

C Moment-duration of a triggered moment: $\mathbf{C}_{\mathbf{y x}}=\mathbf{C}_{\mathbf{x y}}=\mathbf{C}$.

$M$ Duration of a psychological moment.

CDF Cumulative density function.

$\mathrm{F}_{\mathbf{M}} \mathrm{CDF}$ of $\mathbf{M}$.

$\mathbf{f}_{\mathbf{M}}$ Density of $\mathbf{M}$.

$\mathbf{R}$ Residual-moment duration; also residual of $\mathbf{Q}$.

Q Time quantum; conceived as a random variable.

$q$ Time quantum; conceived as a constant value.

$f_{\mathbf{c}_{x y}}\left(f_{c_{y x}}\right)$ Density of $C_{x y}\left(C_{y x}\right)$.

$p_{\mathrm{x}}\left(p_{\mathrm{y}}\right)$ Probability that attention is initially directed to channel $x(y)$.

$\mathbf{D}_{\mathbf{M}}$ Random variable that can be conceived as a mixture of $\mathbf{D}_{\mathbf{L}}$ and $\mathbf{D}_{\mathbf{R}}$.

$Y_{\mathrm{M}}$ Psychometric function defined as $Y_{\mathbf{M}}(d) \equiv$ $\operatorname{Pr}\left\{x y_{\mathrm{su}} \mid d\right\}+\operatorname{Pr}\left\{x y_{\mathrm{SI}} \mid d\right\}$.

$\beta$ Response bias for $x y_{\mathrm{U}}\left(x y_{\mathrm{SI}}\right)$.

$m_{\mathrm{r}}^{\prime}$ Estimate of the $r$ th raw moment of $\mathbf{D}$.

$p_{\mathrm{i}}$ Estimate of $Y\left(d_{\mathrm{i}}\right)$.

$M$ Estimate of the mean of $\mathbf{D}$.

$S D$ Estimate of the standard deviation of $\mathbf{D}$.

$S K$ Estimate of the skewness of $D$, that is, estimate of $\left(E\left\{[E(D)-D]^{3}\right\}\right)^{1 / 3}$.

SE Standard error of estimate.

(Manuscript received October 30, 1986;

revision accepted for publication March 11, 1987.) 